\title{
Activation of MDL-1 (CLEC5A) on immature myeloid cells triggers lethal shock in mice
}

\author{
Ricky Cheung, Fran Shen, Joseph H. Phillips, Mandy J. McGeachy, \\ Daniel J. Cua, Paul G. Heyworth, and Robert H. Pierce \\ Discovery Research, Merck Research Laboratories, Palo Alto, California, USA.
}

\begin{abstract}
Systemic inflammatory response syndrome (SIRS) is a potentially lethal condition, as it can progress to shock, multi-organ failure, and death. It can be triggered by infection, tissue damage, or hemorrhage. The role of tissue injury in the progression from SIRS to shock is incompletely understood. Here, we show that treatment of mice with concanavalin A (ConA) to induce liver injury triggered a G-CSF-dependent hepatic infiltration of $\mathrm{CD} 11 \mathrm{~b}^{+} \mathrm{Gr}-1^{+} \mathrm{Ly} 6 \mathrm{G}^{+} \mathrm{Ly} 6 \mathrm{C}^{+}$immature myeloid cells that expressed the orphan receptor myeloid DAP12-associated lectin-1 (MDL-1; also known as CLEC5A). Activation of MDL-1 using dengue virus or an agonist MDL-1-specific antibody in the ConA-treated mice resulted in shock. The MDL-1 ${ }^{+}$cells were pathogenic, and in vivo depletion of MDL- $1^{+}$cells provided protection. Triggering MDL-1 on these cells induced production of NO and TNF- $\alpha$, which were found to be elevated in the serum of treated mice and required for MDL-1-induced shock. Surprisingly, MDL-1-induced NO and TNF- $\alpha$ production required eNOS but not iNOS. Activation of DAP12, DAP10, Syk, PI3K, and Akt was critical for MDL-1-induced shock. In addition, Akt physically interacted with and activated eNOS. Therefore, triggering of MDL-1 on immature myeloid cells and production of NO and TNF- $\alpha$ may play a critical role in the pathogenesis of shock. Targeting the MDL-1/Syk/PI3K/Akt/eNOS pathway represents a potential new therapeutic strategy to prevent the progression of SIRS to shock.
\end{abstract}

\section{Introduction}

Activation of the innate immune system is a common feature of the systemic inflammatory response syndrome (SIRS), whether the initial trigger is infection or sterile tissue damage in trauma or hemorrhage. Activation of myeloid lineage cells, including monocytes, macrophages and neutrophils, leads to the production of proinflammatory cytokines as well as other mediators of tissue injury, such as ROS and reactive nitrogen species. Organ injury, in turn, induces the release of damage-associated molecular patterns (DAMPs) such as mitochondrial DNA, heat shock proteins (HSPs), and high-mobility group box 1 (HMGB1) that amplify the ongoing innate inflammatory response, which can progress to shock, multi-organ failure, and death (1). The progression to shock, defined as the systemic loss of blood pressure, has been attributed to cytokine-mediated capillary leakage and pathologic vasodilation, in which both TNF- $\alpha$ and NO have been implicated as critical mediators (2). Although the systemic release of TNF- $\alpha$ and NO may represent the catastrophic "tipping point" in the progression from SIRS to shock, many of the key cellular and molecular mechanisms involved in this pathophysiological decompensation remain to be elucidated, and these may represent key points of medical intervention.

Understanding the factors that drive the progression from dengue virus (DV) infection to lethal dengue shock syndrome (DSS) is of particular medical importance. DV infection is the most prevalent arboviral disease worldwide, with an estimated yearly incidence of 50 million cases. Although primary infection with one of the 4 DV serotypes usually results in mild disease, secondary infection with a second serotype conveys significant risk for the development of life-threatening DSS. In addition

Conflict of interest: The authors have declared that no conflict of interest exists. Citation for this article: J Clin Invest. 2011;121(11):4446-4461. doi:10.1172/JCI57682. to the clear risks of previous exposure and production of nonneutralizing antibodies specific to the primary DV serotype, the progression from secondary dengue infection to DSS correlates with high levels of circulating TNF, young patient age, and the presence of tissue damage. In particular, liver injury has been implicated as one of the risk factors associated with the development of DSS, as elevated serum ALT and AST levels are a strong predictor for disease severity (3-5). However, the cellular and molecular mechanisms of progression to DSS remain largely unexplored. Recently, vascular leakage and shock were shown to be strictly dependent upon DV particles binding to and signaling through the myeloid-restricted cell surface receptor myeloid DAP12-associating lectin-1 (MDL-1) (6). Two recently published articles further highlight the importance of MDL-1 in DV-induced disease. One study reports that $M D L-1$ gene expression is a critical factor in differentiating dengue hemorrhagic fever (DHF) from dengue fever (DF) patients, while another article suggests blocking DV/MDL-1 interaction as a potential antiviral therapy $(7,8)$.

MDL-1, also known as C-type lectin domain family 5 member A (CLEC5A), is a type II transmembrane protein and a member of the C-type lectin superfamily. MDL-1 has a short cytoplasmic tail and lacks signaling motifs, therefore requiring association with the adaptor protein DAP12 to generate signals (9). However, the downstream signaling pathways triggered by MDL-1 are not well defined. Functionally, MDL-1 activation has been shown to induce production of cytokines (TNF- $\alpha$, IL-1, IL-6, IL-8, IL-17A) and chemokines (MIP-1 $\alpha$, RANTES, IP-10, MDC) $(6,10,11)$. Like triggering receptor expressed on myeloid cells-1 (TREM-1), which potentiates myeloid cell activation and cytokine release in response to TLR ligands and other pathogen-associated molecular patterns (PAMPs), MDL-1 appears to function as an amplifier of the innate immune response. 
The endogenous ligand for MDL-1 has yet to be identified. However, dengue viral particles can clearly function as a proinflammatory PAMP at the MDL-1 receptor to induce shock in the context of a productive DV infection. However, in our experience, systemic activation of MDL-1 in uninfected naive mice results in no significant pathology or systemic cytokine production. Based on this, we hypothesized that an initial trigger of tissue injury was required to predispose the system to an MDL-1-induced shock response. To test this hypothesis, we employed a sublethal dose of concanavalin A (ConA) to induce nonlethal liver injury, and found that this injury did indeed sensitize mice to shock induced by triggering of MDL-1. In brief, we demonstrate that ConA induces a mobilization and hepatic accumulation of myeloid cells with an immature phenotype $\left(\mathrm{CD} 11 \mathrm{~b}^{+} \mathrm{Gr} 1^{+} \mathrm{Ly} 6 \mathrm{G}^{+} \mathrm{Ly} 6 \mathrm{C}^{+}\right)$that express MDL- 1 and are necessary to sensitize the mouse to MDL-1-induced shock. Furthermore, the MDL-1-mediated shock was surprisingly dependent on eNOS-induced, but not iNOS-induced, NO, as well as TNF- $\alpha$ production. This study for the first time to our knowledge delineates cellular and molecular mechanisms involved in the progression from tissue injury to shock that are driven by the pathologic expansion and activation of immature myeloid cells coexpressing MDL-1 and eNOS.

\section{Results}

Activation of MDL-1 induces shock. Intravenous administration of ConA causes liver injury (12). Using a novel bioluminescent inflammation probe (13) and in vivo imaging technology (Figure 1A), we confirmed that this ConA-induced inflammation was highly liver specific, while no inflammation signal was detected in naive mice (data not shown). We also observed that MDL- $1^{+}$cells accumulated in the liver in response to ConA-induced liver inflammation in a time-dependent fashion, with maximal infiltration occurring at 4 hours after ConA treatment (Figure 1, B and C). Since the endogenous ligand for MDL-1 has not yet been identified, we activated MDL-1 in vivo by injecting DV, the only molecule known to interact with MDL-1. Activation of MDL-1 by intraperitoneal injection of DV 4 hours after ConA treatment resulted in lethal shock with onset at 12 hours. Almost all $M D L-1^{-/-}$mice were protected, thus confirming that death triggered by DV is mediated via MDL-1 (Figure 1D).

In order to avoid undesirable triggering of other signaling pathways, such as TLR, by the DV preparation, we also generated antimouse MDL-1 agonist mAb (10) and used it to activate MDL-1 in vivo. Interestingly, mice injected with anti-MDL-1 mAb also died of shock, albeit with a much earlier onset of approximately 15 minutes, and this rapid death was mediated via MDL-1, as all $M D L-1^{-1-}$ mice were protected (Figure 1E). This rapid onset of MDL-1-triggered death could be delayed by titration of the dose of agonist $\mathrm{mAb}$ injected in a dose-dependent manner, and all mice injected with anti-MDL-1 antagonist $\mathrm{mAb}$ or $\mathrm{IgG}_{1}$ isotype control survived (Figure 1, F and G), further confirming that the observed shock response is mediated via activation of MDL-1. Of note, in the absence of ConA treatment, administration of DV or agonist $\mathrm{mAb}$ to mice resulted in no death (data not shown), indicating that prior liver injury is crucial in sensitizing the animal to shock triggered by MDL-1.

Hepatic infiltration of $M D L-1^{+}$cells is G-CSF dependent. To further understand the mechanism by which ConA initiates the infiltration of MDL- $1^{+}$cells to the liver, we measured the levels of 15 different chemokines and growth factors in both serum and liver homogenates of mice treated with ConA for 0-4 hours. Of the 15 chemokines and growth factors tested, we focused on G-CSF, GMCSF, KC, MIP-2, and MCP-1, all of which have been implicated in the mobilization and/or maturation of myeloid precursors, neutrophils, and monocytes. The G-CSF level in both the serum and liver was increased by ConA in a time-dependent fashion (Figure 2A). To elucidate whether this growth factor plays a role in MDL-1-mediated shock, we neutralized G-CSF before initiation of MDL-1 ${ }^{+}$cell mobilization by ConA. As shown in Figure 2B, ablation of G-CSF significantly ameliorated MDL-1-triggered lethal shock. G-CSF level in the blood and liver of these mice was measured, and the results indicated that G-CSF was suppressed by $100 \%$ and 50\%, respectively (Figure 2C). Liver sections of these mice were stained for MDL-1 and showed a $46 \%$ decrease in hepatic infiltration of MDL-1+ $1^{+}$cells in mice subjected to G-CSF neutralization (Figure 2D). These results indicated that G-CSF is an important growth factor for the hepatic infiltration of MDL- $1^{+}$cells and that ablation of this growth factor confers protection against MDL-1-mediated lethal shock.

In addition to G-CSF, production of other growth factors and chemokines including GM-CSF, KC, MIP-2, and MCP-1 was also increased by ConA in a time-dependent manner, with slightly different kinetics (Supplemental Figure 1A; supplemental material available online with this article; doi:10.1172/JCI57682DS1). However, neutralization of GM-CSF, KC, or MIP-2 had no effect on survival (Supplemental Figure 1, B-D). MCP-1 is also not important for MDL-1-mediated shock, since mice that lack CCR2, the cognate receptor for MCP-1, showed survival similar to that of WT mice (Supplemental Figure 1E). Therefore, G-CSF seems to be the predominant factor driving recruitment of $\mathrm{MDL}-1^{+}$cells to the liver.

Intravenous administration of G-CSF also drove hepatic infiltration of MDL- $1^{+}$cells (Supplemental Figure 2, A and B), but subsequent administration of MDL-1 agonist $\mathrm{mAb}$ resulted in no death (data not shown). We therefore hypothesized that priming of MDL- $1^{+}$cells is required for these cells to be responsive to MDL-1 stimulation. In addition to chemokines, ConA also increased serum levels of multiple cytokines, including IFN- $\gamma$, TNF- $\alpha$, IL$1 \beta$, and IL-6 (Supplemental Figure 2, C-F), all of which have been reported to be effective priming agents for immune cells $(14,15)$. To test the hypothesis that cytokine-induced activation is required for the priming of MDL-1-triggered shock, we treated mice first with G-CSF to mobilize MDL- $1^{+}$cells, then IFN- $\gamma$, TNF- $\alpha$, IL- $1 \beta$, and IL-6. When agonist MDL-1 mAb or DV was administered, all primed mice died (Supplemental Figure 2, G and H), while all cytokine-primed mice treated with isotype control $\mathrm{mAb}$ and primed $M D L-1^{-/-}$mice triggered with DV survived.

We then asked whether other forms of liver damage may also predispose mice toward MDL-1-induced shock. As shown in Supplemental Figure 3A, intraperitoneal administration of a sublethal dose of acetaminophen (APAP) caused liver injury (assessed by serum ALT levels) in a time-dependent manner (16). Similar to ConA-induced liver inflammation, we also observed a time-dependent increase in hepatic infiltration of $\mathrm{MDL}-1^{+}$cells in response to APAP treatment, with maximal recruitment occurring at 8 hours after APAP administration (Supplemental Figure 3 , B and C). However, hepatic infiltration of MDL- $1^{+}$cells was 7-fold lower in response to APAP compared with ConA treatment (Figure $1, B$ and $\mathrm{C}$ ). In vivo activation of MDL-1 by administration of anti-MDL-1 mAb 8 hours after APAP treatment caused no death, while all mice died within 45 minutes with prior ConA treatment (Supplemental Figure 3D). We also measured serum G-CSF levels in APAP-treated mice and observed a 30-fold lower 
A

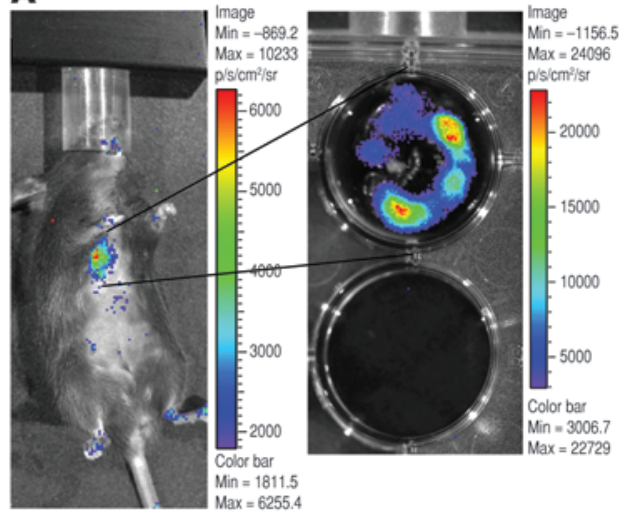

B
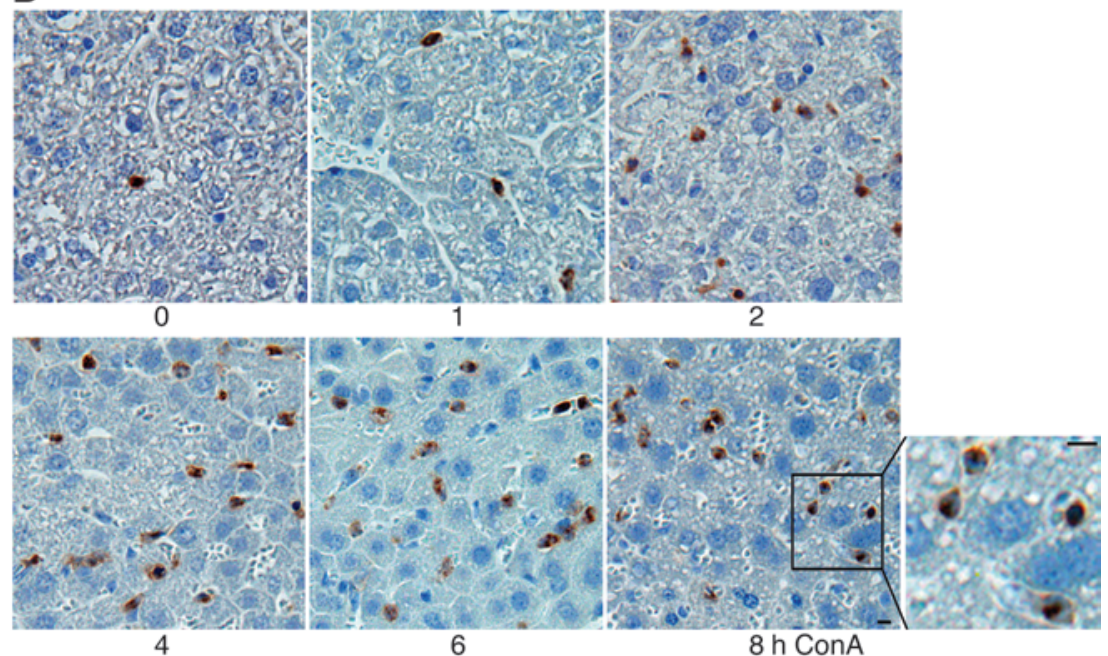

4

D

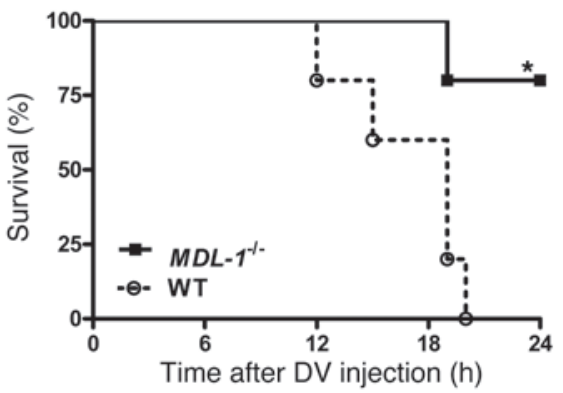

E

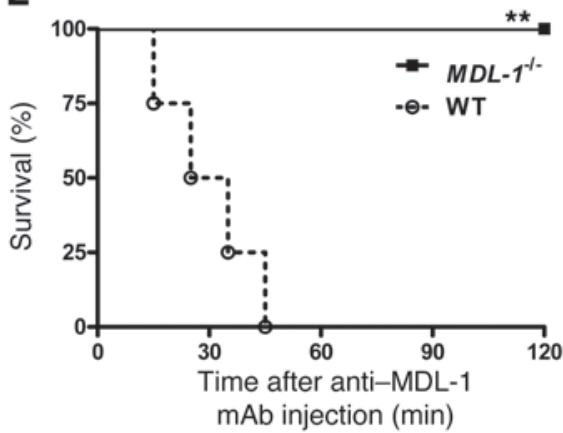

$\mathbf{F}$

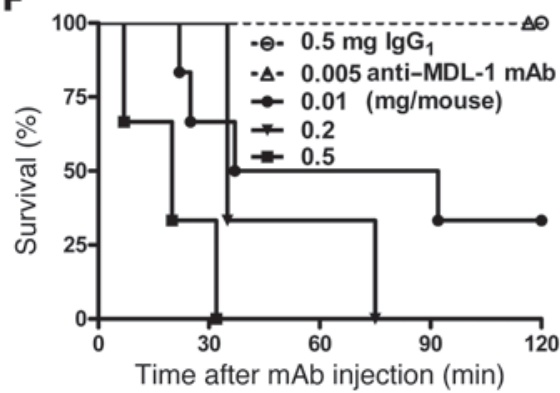

G

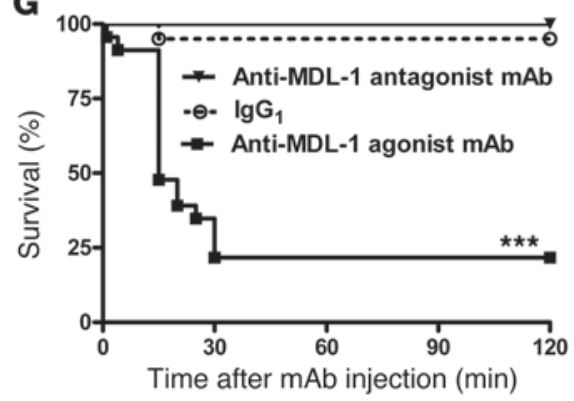

Figure 1

Recruitment and activation of MDL-1+ cells led to lethal shock in mice. (A) C57BL/6 mice were injected with inflammation probe after ConA treatment and monitored for inflammation (left panel). After in vivo imaging, mice were sacrificed and livers were excised for ex vivo imaging (right panel). p, photons; sr, steradians. (B) Mice were treated with ConA for the indicated times $(n=5)$, and liver sections were stained with anti-MDL-1 $\mathrm{mAb}$. The inset shows high magnification of MDL-1+ cells. Scale bars: $10 \mu \mathrm{m}$. (C) Quantitation of MDL-1+ cells in $\mathbf{B}$. ${ }^{*} P<0.05$, ${ }^{* * *} P<0.001 \mathrm{com}-$ pared with 0 hours. (D and E) MDL-1-1- and WT mice were treated with ConA, followed by (D) DV or (E) anti-MDL-1 mAb $(n=5)$, and survival was monitored. ${ }^{*} P<0.05,{ }^{* *} P<0.01$ compared with WT. (F) Mice were treated with ConA, followed by the indicated doses of anti-MDL-1 mAb $(n=3)$, and survival was monitored. (G) Mice were treated with ConA, followed by $\operatorname{lgG}_{1}(n=20)$, anti-MDL-1 agonist $(n=23)$, or antagonist $(n=5)$ mAb, and survival was monitored. ${ }^{* \star *} P<0.001$ compared with $\lg _{1}$.

induction compared with mice receiving ConA treatment (Supplemental Figure 3E). Therefore, there appears to be a threshold of cellular infiltration that needs to be reached before MDL-1 triggering results in shock. In addition to G-CSF, APAP-treated mice also showed markedly lower serum levels of cytokines including IFN- $\gamma$, TNF- $\alpha$, IL- $1 \beta$, and IL- 6 (Supplemental Figure $3, \mathrm{~F}-\mathrm{I}$ ), which we have shown to be critical for priming.
$M D L-1-$ expressing cells are $C D 11 b^{+} G r-1^{+}$immature myeloid cells. For identification of the cell type that expressed MDL-1, infiltrating leukocytes were isolated from ConA-treated livers, enriched by CD45 microbeads, and immunophenotyped by flow cytometry. As shown in Figure 3A, 88\% of the CD $45^{+}$leukocytes infiltrating the liver in response to ConA were $\mathrm{CD} 11 \mathrm{~b}^{+}$, and more than $95 \%$ of the $\mathrm{CD} 11 \mathrm{~b}^{+}$cells were also positive for $\mathrm{Gr}-1$. CD $11 \mathrm{~b}^{+}$myeloid 
A
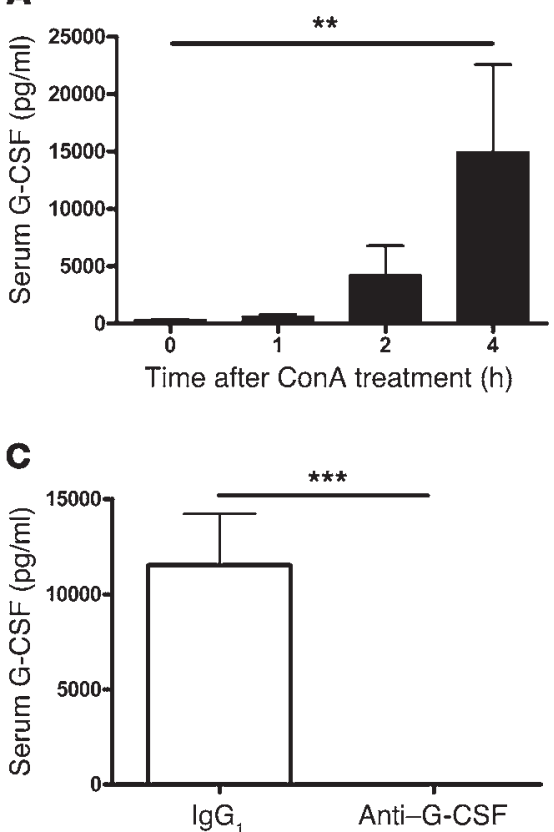

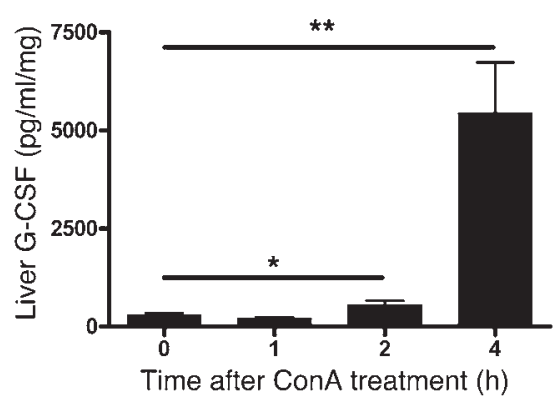

B
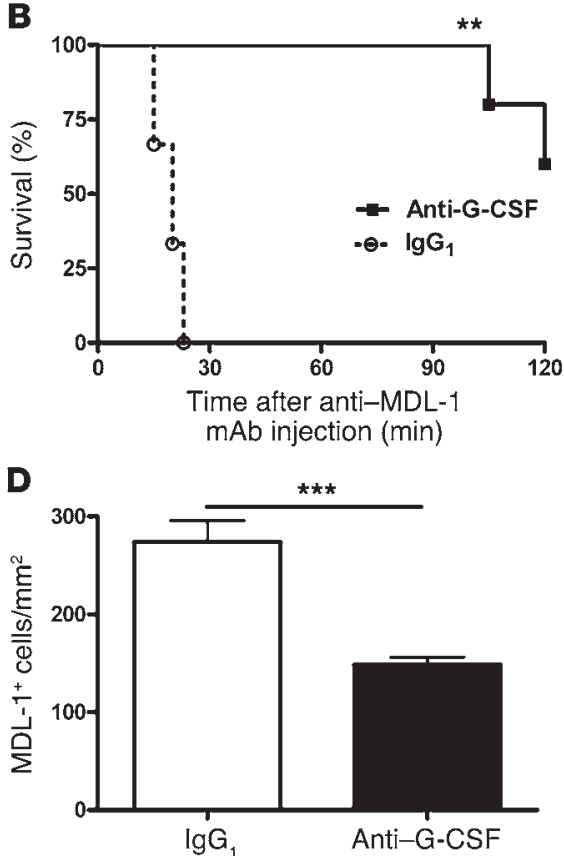

Figure 2

G-CSF is important for MDL-1-mediated shock. (A) Serum and liver homogenates were obtained from mice treated with ConA for the indicated times $(n=5)$, and G-CSF levels were quantitated by Luminex. ${ }^{*} P<0.05$, ${ }^{* *} P<0.01$ compared with 0 -hour time point. (B) Mice were pretreated with anti-G-CSF neutralizing antibodies $(n=5)$ or $\operatorname{lgG}_{1}(n=3)$ prior to administration of ConA, followed by anti-MDL-1 mAb, and survival was monitored. ${ }^{* *} P<0.01$ compared with $\operatorname{lgG}_{1}$. (C) Blood and livers were collected from the mice represented in B, and G-CSF levels in the serum and liver homogenates were measured to evaluate the efficiency of G-CSF neutralization. ${ }^{* *} P<0.01,{ }^{* * *} P<0.001$ compared with $\operatorname{lgG}_{1}$. (D) Liver sections collected from the mice represented in B were immunostained with anti-MDL-1 mAb, and positively stained cells were quantitated $(n=5)$. ${ }^{\star \star *} P<0.001$ compared with $\lg _{1}$.

cells were further characterized with the lineage-specific markers Ly6G (neutrophils) and Ly6C (monocytes) $(17,18)$. When $\mathrm{CD} 11 \mathrm{~b}^{+}$cells were gated for Ly6G and Ly6C expression (Figure $3 \mathrm{~A})$, the majority $(85.3 \%)$ of these cells were Ly6G+ $\mathrm{Ly}^{+} \mathrm{C}^{\mathrm{lo}}$ (red ellipsoid), with two smaller cell populations that were Ly6 $\mathrm{G}^{-}$ Ly6Chi (green ellipsoid) and Ly6G-Ly6C lo (blue ellipsoid). When these three cell populations were further analyzed for MDL-1 expression (Figure $3 \mathrm{~A}$ ), the predominant $\mathrm{Ly} 6 \mathrm{G}^{+} \mathrm{Ly} 6 \mathrm{C}^{\mathrm{lo}}$ cell population (red curve) expressed the highest levels of MDL-1, followed by the Ly6G-Ly6Chi (green curve) and Ly6G-Ly6C lo cells (blue curve), suggesting that the majority of the MDL-1+ cells were granulocytic in nature. Of note, MDL-1 was not primarily expressed on macrophages, as the majority (61\%) of these cells were $\mathrm{CD} 11 \mathrm{~b}^{+} \mathrm{F} 4 / 80^{-}$and only a small population $(5 \%)$ was double positive, as shown in the red and blue boxes, respectively, in Supplemental Figure 4A. When these two cell populations were further analyzed for MDL-1 expression, they both expressed similar levels of MDL-1. In addition, the F4/80 staining on livers isolated from mice treated with ConA showed a similar prevalence of $\mathrm{F} 4 / 80^{+}$cells across all of the ConA time points (Supplemental Figure 4B). This also suggests that the F4/80 staining detected liver residential Kupffer cells and not the infiltrating MDL- $1^{+}$cells shown in Figure 1B. Furthermore, the morphology of the F4/80-stained cells with long pseudopods is consistent with macrophages/Kupffer cells and is distinct from the round morphology of MDL-1-stained cells (high-magnification image shown in the inset of Figure 1B). Taken together, our results indi- cated that MDL-1 is primarily expressed on granulocytic myeloid cells. When comparing the total number and the percentage of MDL- $1^{+} \mathrm{Ly} 6 \mathrm{G}^{+} \mathrm{Ly} 6 \mathrm{C}^{\text {lo }}$ cells isolated from livers of naive and ConAtreated mice, there was a 40 -fold increase in the percentage ( $0.096 \%$ to $3.8 \%$ of leukocytes/liver) and 46 -fold increase in the number ( 0.02 to 1.49 million/liver) of MDL- $1^{+}$cells in the liver in response to ConA treatment (Figure 3B).

Cytospin was performed next to visualize the morphology of these infiltrating cells. As shown in Figure 3C, the Gr-1-enriched cell population from the livers of ConA-treated mice showed a large number of morphologically heterogeneous cells. Many of these cells were relatively large $(\sim 10 \mu \mathrm{m})$, with ring-shaped nuclei (indicated by arrowheads), which is consistent with immature myeloid cells (19). The number of ring cells decreased significantly in the Cytospin preparation of cells isolated from naive mice (left panel), suggesting that the hepatic infiltration of these cells is ConA-dependent. In addition to the isolated and enriched cell preparation, immature myeloid cells were also found in the native liver tissue (Figure 3D). The ring cells could be observed primarily in the sinusoid area of ConA-treated liver (as indicated by arrows), but not in the naive liver. The immature phenotype of the MDL-1 $1^{+}$cells was further characterized by flow cytometry using myeloid precursor and progenitor cell-specific markers including CD33, CD34, and MHC class I and II (20-22). In addition to the ring cell morphology, our results showed that MDL- $1^{+}$cells expressed CD33 and MHC class I, but not CD34 or MHC class II (Supplemental Figure 5), further indicating 
A

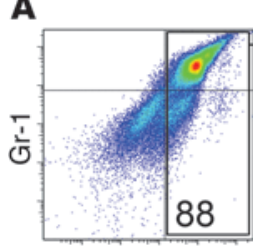

CD11b

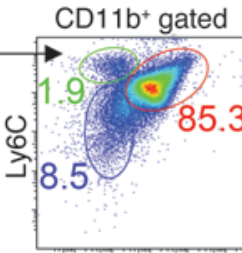

Ly6G

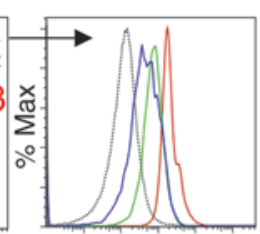

MDL-1
B

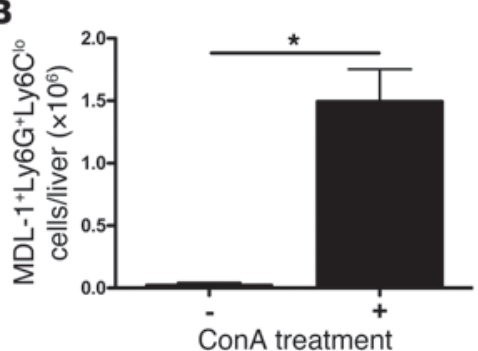

D

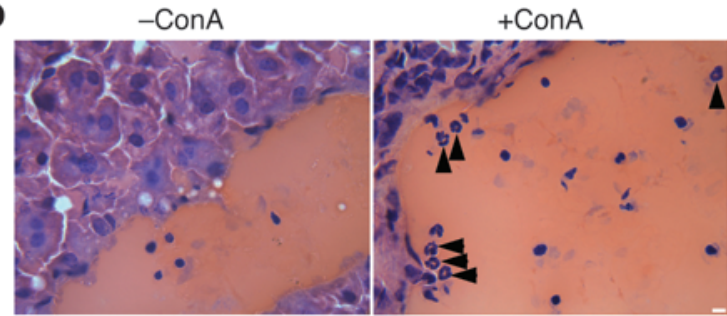

C

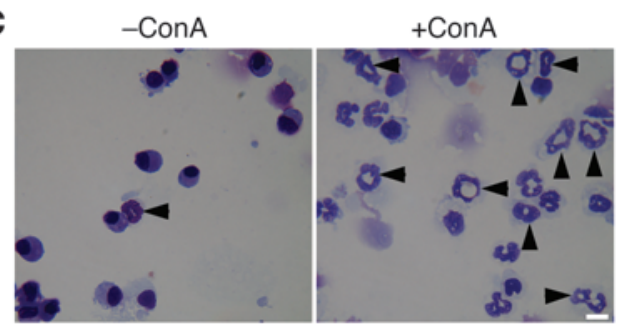

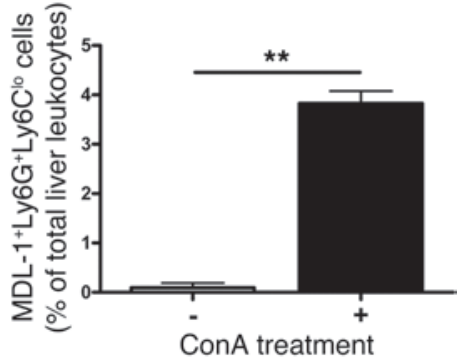

ConA treatment

E DAPI

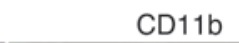

MDL-1 Merge
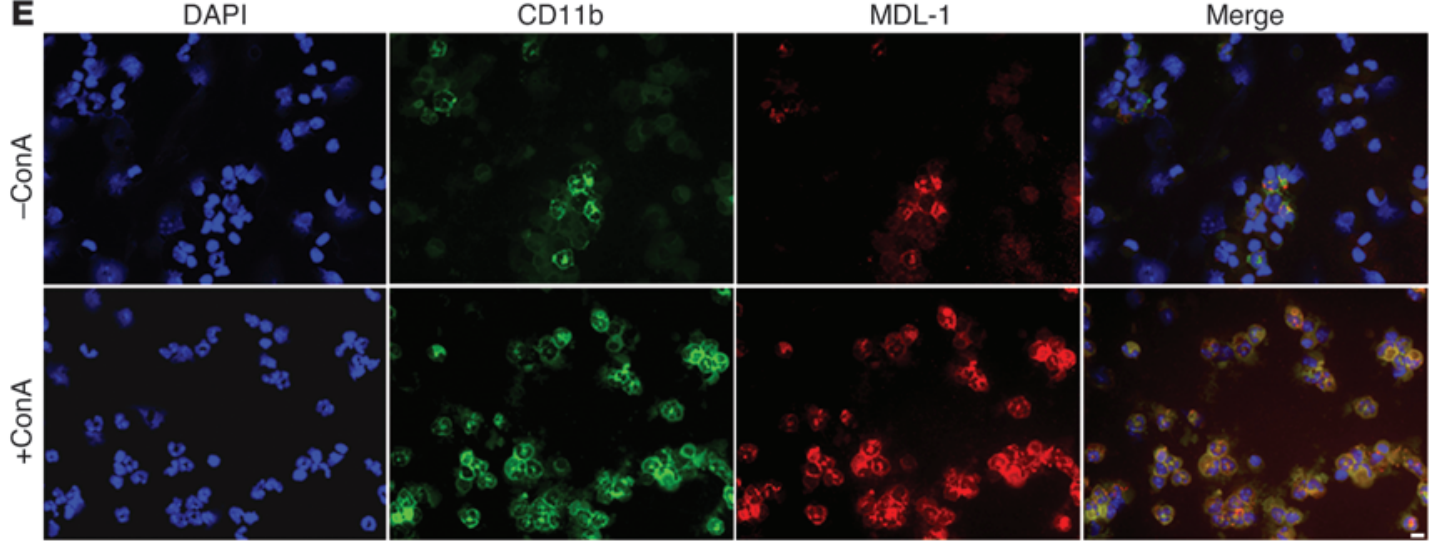

Figure 3

MDL-1+ cells are CD11b+Ly6G+Ly6C+, with ring-shaped nuclei. (A) Leukocytes isolated from livers of ConA-treated mice were purified using CD45 microbeads and analyzed by flow cytometry for expression of CD11b, Gr-1, Ly6G, Ly6C, and MDL-1 gated on CD45+ cells. Background signal was established in the same population by staining with the matched isotype controls. Numbers indicate the percentages of Ly6G+Ly6Clo (red ellipsoid), Ly6G-Ly6Chi (green ellipsoid), and Ly6G-Ly6Clo (blue ellipsoid) cell populations. The individual population was analyzed for MDL-1 expression (dotted line indicates isotype control). (B) Quantitation of MDL-1+Ly6G+Ly6C ${ }^{10}$ cells isolated from livers of naive and ConA-treated mice by flow cytometry. ${ }^{\star} P<0.05,{ }^{\star *} P<0.01$ compared with naive cells. (C) Morphologic analysis of Diff-Quik-stained Cytospin preparations of Gr-1+ cells isolated from livers of naive and ConA-treated mice. Note the increased number of cells with ring-shaped nuclei (indicated by arrowheads) with ConA treatment. Scale bar: $10 \mu \mathrm{m}$. (D) Representative micrographs of H\&E-stained liver sections from naive and ConA-treated mice. ConA treatment increased the number of cells with ring-shaped nuclei as indicated by arrowheads. Scale bar: $10 \mu \mathrm{m}$. (E) Representative micrographs of immunostained Cytospin preparations of $\mathrm{Gr}-1^{+}$cells isolated from livers of naive and ConA-treated mice. Cells were stained with antibodies against CD11b (green) and MDL-1 (red). Nuclei were counterstained with DAPI (blue). Scale bar: $10 \mu \mathrm{m}$.

that MDL- 1 is expressed primarily on immature myeloid cells. G-CSFR (or CD114) was also highly expressed on MDL- $1^{+}$cells, which is consistent with our results demonstrating the importance of G-CSF in mobilizing these MDL- $1^{+}$cells.

As shown in Figure 3E, immunofluorescence staining with anti-mouse antibodies for CD11b and MDL-1 was performed on Gr-1-enriched cells isolated from livers of naive and ConAtreated mice. When the same number of cells was examined on Cytospin preparation (as indicated by equal DAPI staining), there was markedly more nuclei staining with ring-shaped morphology in the ConA-treated cell preparation. The same cell preparation also showed increased staining for CD11b and MDL-1. Further- more, CD11b and MDL-1 were colocalized, in particular in cells with ring-shaped nuclei, as seen by the yellow staining in the merge image. The results together identified the MDL-1 ${ }^{+}$cells infiltrating the liver in response to ConA as immature myeloid cells with ring-shaped nuclei.

$M D L-1^{+}$immature myeloid cells are pathogenic in lethal shock. We set out to ascertain whether the MDL-1+ ${ }^{+}$immature myeloid cells are the primary pathogenic cells in our model by performing both adoptive transfer and in vivo depletion experiments. Control mice that received $\mathrm{CD} 11 \mathrm{~b}^{+}$cells ( $\sim 85 \%$ pure) and isotype control $\mathrm{mAb}$ did not show any sign of shock (Figure 4A). However, injection of anti-mouse MDL-1 mAb triggered lethal shock. Shock was depen- 
A

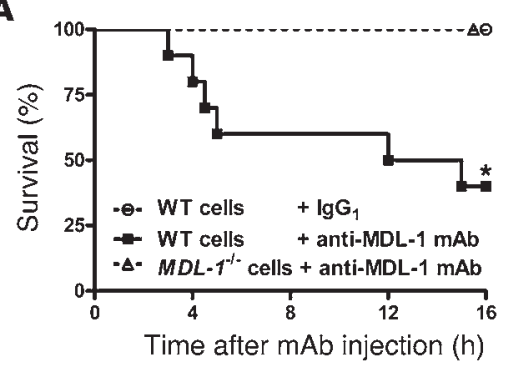

B

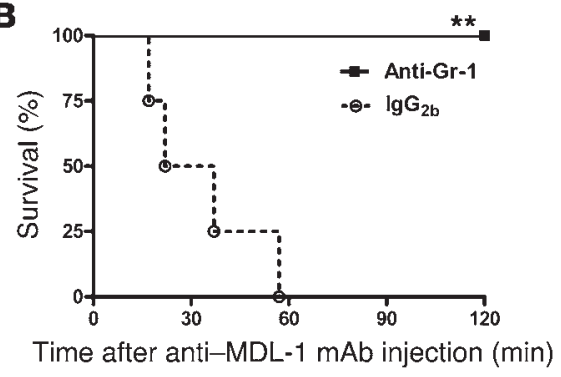

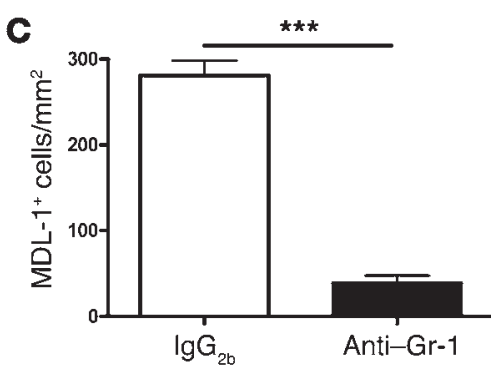

Figure 4

CD11b+Gr-1+ cells are pathogenic in MDL-1-mediated shock. (A) CD11 b+ cells were isolated from livers of ConA-treated WT or MDL-1-/- mice and injected into naive WT recipient mice via tail vein $(n=10)$. Anti-MDL-1 mAbs were injected 30 minutes after transfer, and survival was monitored. ${ }^{*} P<0.05$ compared with $\operatorname{lgG}_{1}$ or transfer cells from MDL-1-1- mice. (B) Mice were pretreated with anti-Gr-1 mAb $(n=5)$ or IgG $\mathrm{m}_{2 b}(n=4)$ prior to administration of ConA, followed by anti-MDL-1 mAb, and survival was monitored. ${ }^{\star \star} P<0.01$ compared with IgG $\mathrm{G}_{2 \mathrm{~b}}$. (C) Liver sections from $\mathbf{B}$ were immunostained with anti-MDL-1 mAb, and positively stained cells were quantitated $(n=5)$. ${ }^{\star \star \star} P<0.001$ compared with $\lg _{2 \mathrm{~b}}$.

dent on MDL-1 expression on transferred cells, since recipients of $M D L-1^{-/-}$cells were resistant to anti-MDL-1 mAb effects. The number of cells transferred to the recipient mice was also an important determinant of pathogenicity, since animals injected with fewer than $15 \times 10^{6} \mathrm{CD} 11 \mathrm{~b}^{+}$cells were protected from MDL-1-triggered shock (data not shown). The MDL- $1^{+}$cells could be detected in the livers as early as 30 minutes after transfer and remained present after 16 hours (data not shown).

In the converse experiment, in vivo depletion of $\mathrm{Gr}-1^{+}$cells conferred complete protection from MDL-1-induced shock (Figure $4 \mathrm{~B})$. Liver sections of these mice were stained for MDL-1 and showed an $86 \%$ decrease in hepatic infiltration of MDL- $1^{+}$cells in mice treated with Gr-1-specific depletion antibody (Figure 4C). Together, these data provide concrete evidence that MDL-1 ${ }^{+}$ immature myeloid cells are pathogenic in causing lethal shock.

Activation of MDL- $1^{+}$cells induces NO and TNF- $\alpha$ production. Both NO and TNF- $\alpha$ have previously been identified as potential mediators of shock, triggering hemodynamic collapse (23-26). To test whether these pathogenic immature myeloid cells are capable of producing NO and TNF- $\alpha$ in response to MDL- 1 stimulation, we isolated cells and stimulated them in vitro, and the levels of NO and TNF$\alpha$ in the culture media were measured. In response to anti-MDL-1 $\mathrm{mAb}$ stimulation, $\mathrm{CD} 11 \mathrm{~b}^{+}$cells isolated from WT mice were able to induce both NO and TNF- $\alpha$ production, while such an increase was absent in $M D L-1^{-/-}$mice (Figure 5A). To expand our results with the more pathologically relevant stimulator of MDL-1, we also tested the ability of DV to trigger $\mathrm{CD} 11 \mathrm{~b}^{+}$cells to produce these mediators and showed that DV treatment was able to stimulate both $\mathrm{NO}$ and TNF- $\alpha$ release, and in an MDL-1-dependent fashion (Figure 5B).

We also tested the ability of agonist mAb or DV to trigger MDL-1 in an ex vivo bioassay of liver slice culture, which has the advantage of retaining a tissue-specific microarchitecture environment and cell diversity. Precision-cut tissue slices were obtained from livers of ConA-treated WT and $M D L-1^{-/-}$mice and exposed to anti-MDL-1 $\mathrm{mAb}$ or $\mathrm{DV}$. Incubation of anti-MDL-1 $\mathrm{mAb}$ in liver slice culture elevated levels of NO and TNF- $\alpha$, and such increases were abolished in liver slices from $M D L-1^{-/}$mice (Figure 5C). Exposure of liver slices to DV also increased NO and TNF- $\alpha$ production, and such upregulation was attenuated in $M D L-1^{-/-}$liver slices (Figure 5D).

To further establish that these mediators play an important role in vivo in MDL-1-triggered shock, we measured NO and TNF- $\alpha$ levels in the serum of mice treated with ConA and stimulated with
anti-MDL-1 mAb or DV. Mice undergoing MDL-1-induced shock triggered by agonist mAb had elevated levels of NO and TNF- $\alpha$ in their serum compared with isotype control-treated mice (Figure 5E). These increases were primarily due to MDL-1 activation, since they were not seen in the serum of $M D L_{-1}^{-1-}$ mice treated with ConA and agonist $\mathrm{mAb}$. Similarly, there was an upregulation of NO and TNF- $\alpha$ in the serum of mice with DV-triggered lethal shock, while the serum of $M D L-1^{-/-}$mice had significantly lower levels of these two mediators (Figure 5F). These results strongly indicated that activation of MDL-1 on immature myeloid cells triggers production of NO and TNF- $\alpha$, which is associated with an MDL-1-mediated shock response.

NO generated by eNOS is a critical mediator of $M D L-1$-induced shock. To demonstrate that NO is an important mediator of MDL-1-induced shock, we pretreated mice with the NO scavenger carboxy-PTIO (27) prior to MDL-1 activation. Compared with control vehicle, removal of NO by carboxy-PTIO treatment significantly improved the survival rate (Figure 6A). Similar protection was observed when mice were pretreated with the NOS inhibitor L-NAME (Figure 6B).

There are three isoforms of NOS designated according to their expression and regulation pattern: neuronal NOS (nNOS), eNOS, and iNOS. Both nNOS and eNOS are constitutively expressed and activated by an increase in intracellular calcium levels, whereas iNOS is calcium-independent and activated by cytokines (including TNF- $\alpha$ ) via gene transcription. It is generally believed that the low level of NO produced by constitutively expressed nNOS and eNOS executes normal physiological functions, whereas overproduction of $\mathrm{NO}$ by iNOS is responsible for an inflammatory response. We set out to identify the NOS isoform involved using an isoform-specific inhibitor and knockout mice. Mice deficient in iNOS showed a mortality rate similar to WT controls (Figure 6C). On the other hand, mice pretreated with the eNOS inhibitor L-NIO (28) had a significantly higher survival rate compared with those pretreated with control vehicle (Figure 6D). Furthermore, $\mathrm{eNOS}^{-/-}$mice were protected from shock triggered by MDL-1 (Figure $6 \mathrm{E}$ ). Such protection was not due to the inability of MDL- $1^{+}$cells to infiltrate the livers or susceptibility to liver injury, since WT and $\mathrm{NOSS}^{-/-}$mice showed similar hepatic MDL-1 staining and serum ALT levels (data not shown).

TNF- $\alpha$ is an important mediator of MDL-1-induced shock and is modulated by eNOS via regulation of TACE activity. We also used both neutralizing $\mathrm{mAb}$ and knockout mice to show that TNF- $\alpha$ is an important mediator of MDL-1-induced shock. Mice pretreated with the TNF- $\alpha$ neutralizing $\mathrm{mAb}$ exhibited significantly greater protec- 

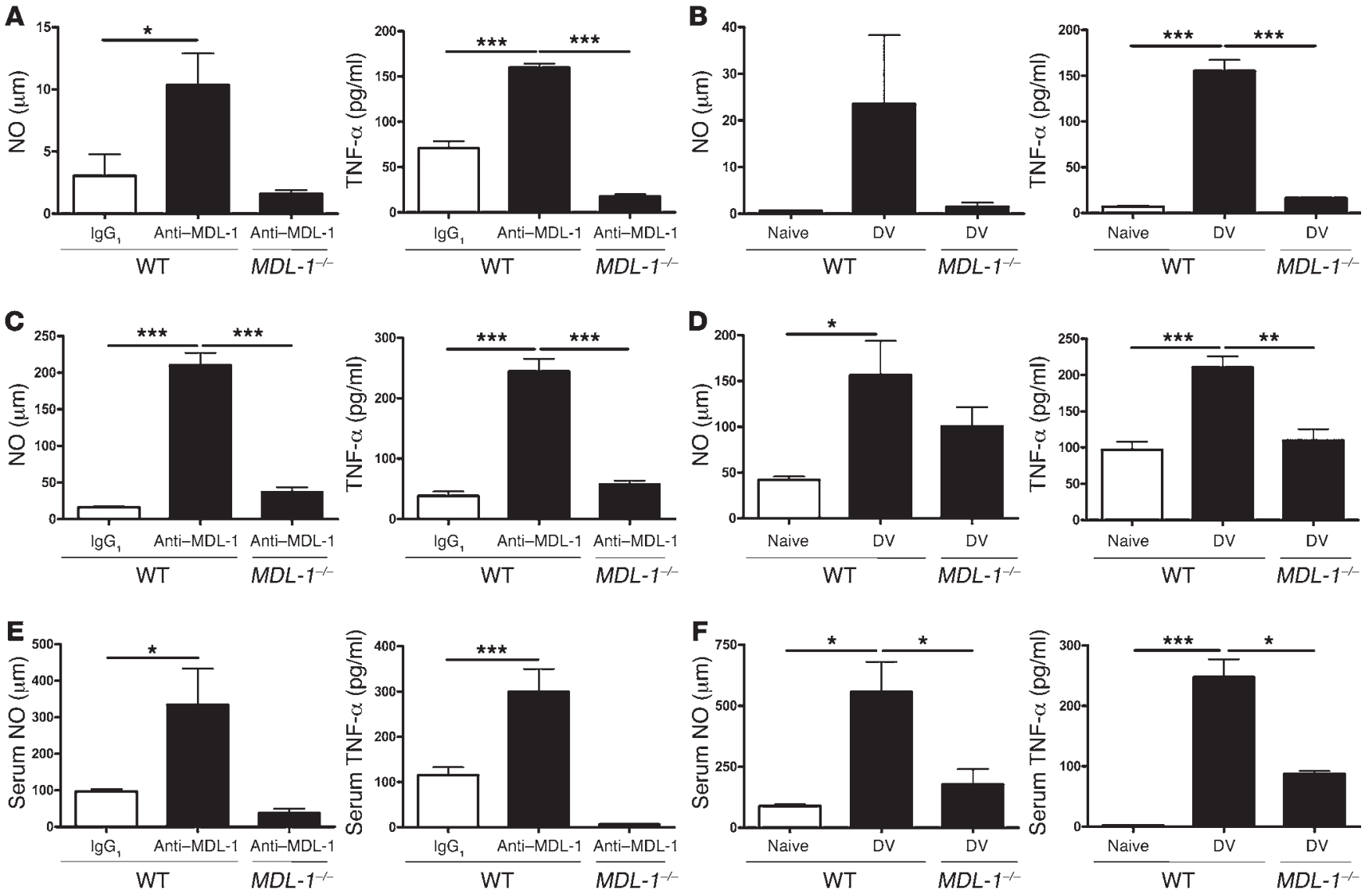

Figure 5

DV-activated MDL- $1^{+}$cells produce NO and TNF- $\alpha$ in vitro, ex vivo, and in vivo. (A and B) CD11 $\mathrm{b}^{+}$cells harvested from livers of ConA-treated WT and MDL-1-1- mice were plated and stimulated with (A) anti-MDL-1 mAb or (B) DV for 24 hours. NO and TNF- $\alpha$ in the conditioned media were measured. Data are mean \pm SEM of triplicates and are representative of 3 independent experiments. ${ }^{*} P<0.05$, ${ }^{* * *} P<0.001$ compared with naive cells from WT or stimulated cells from MDL-1-1- mice. (C and D) Precision-cut liver slices from ConA-treated WT or $M D L-1^{-/-}$mice were plated and stimulated with (C) anti-MDL-1 mAb or (D) DV for 4 hours. NO and TNF- $\alpha$ in the conditioned media were measured. Data are mean \pm SEM of triplicates and are representative of 2 independent experiments. ${ }^{\star} P<0.05$, ${ }^{\star \star \star} P<0.001$ compared with naive liver slices from WT mice or stimulated liver slices from $M D L-1^{-1-}$ mice. (E and F) Serum from WT or $M D L-1^{-1-}$ mice treated with ConA, followed by $(E)$ anti-MDL-1 mAb or $(F)$ DV $(n=5)$, was collected. NO and TNF- $\alpha$ in the serum were measured. ${ }^{*} P<0.05,{ }^{* *} P<0.001$ compared with serum of IgG 1 -treated or naive mice.

tion compared with those treated with control vehicle (Figure 7A). In addition, $\mathrm{Tnfa}^{-/-}$mice had a markedly improved survival rate compared with age-matched controls (Figure 7B). Furthermore, we ruled out defective hepatic infiltration of MDL-1 $1^{+}$cells or less severe liver injury as possible mechanisms of protection seen in $\mathrm{Tnfa}^{-/-}$mice, as they displayed liver MDL-1 staining and serum ALT levels comparable to those in WT mice (data not shown).

Interestingly, the elevated serum TNF- $\alpha$ level seen in WT mice was completely abolished in $\mathrm{eNOS}^{-/-}$mice (Figure 7C), suggesting that eNOS is an upstream regulator of TNF- $\alpha$. Since NO has been shown to activate TACE, the enzyme responsible for the cleavage of the membrane-bound precursor to release the bioactive soluble TNF- $\alpha$ (29), we hypothesized that eNOS-induced NO can modulate TNF- $\alpha$ production by regulating TACE activity. When TACE activity of liver homogenates prepared from WT and eNOS $^{-/-}$mice was measured, there was a modest but significant reduction in $\mathrm{eNOS}^{-/-}$mice (Figure 7D). To further demonstrate that regulating TACE plays an important role in MDL-1-induced shock, we treated mice with the TACE inhibitor TAPI- 1 immedi- ately after ConA administration. Inhibition of TACE markedly improved the survival rate (Figure $7 \mathrm{E}$ ), correlating with attenuated release of TNF- $\alpha$ in the serum (Figure 7F).

To confirm that the MDL-1-expressing immature myeloid cells play a direct role in NO and TNF- $\alpha$ production in response to MDL- 1 stimulation, we performed intracellular staining for eNOS and TNF- $\alpha$ in cells isolated from ConA-treated livers (Figure 7G). When the $\mathrm{CD} 11 \mathrm{~b}^{+}$cell population (top left panel, blue ellipsoid gate) was gated for TNF- $\alpha$ and eNOS expression (lower middle panel), there were two distinct populations of cells that expressed both eNOS and TNF- $\alpha$ : TNF- $\alpha^{+} e N O S^{\text {hi }}$ (red box) and TNF- $\alpha^{+} e N O S^{\text {lo }}$ (green box), and both cell populations were MDL-1 $1^{+}$(lower right panel). TNF- $\alpha^{+} e^{-N O S}{ }^{-}$cells (blue box) were also MDL- $1^{+}$but not TNF- $\alpha^{-}$ eNOS $^{+}$cells (purple box), indicating that all TNF- $\alpha^{+}$cells expressed MDL- 1 but not all eNOS ${ }^{+}$cells were MDL- $1^{+}$. We also stained the cells for iNOS and confirmed that they did not express iNOS protein (Supplemental Figure 6). Taken together, these results indicated that TNF- $\alpha$ - and eNOS-mediated NO production by MDL- $1^{+}$ immature myeloid cells induces lethal shock. 

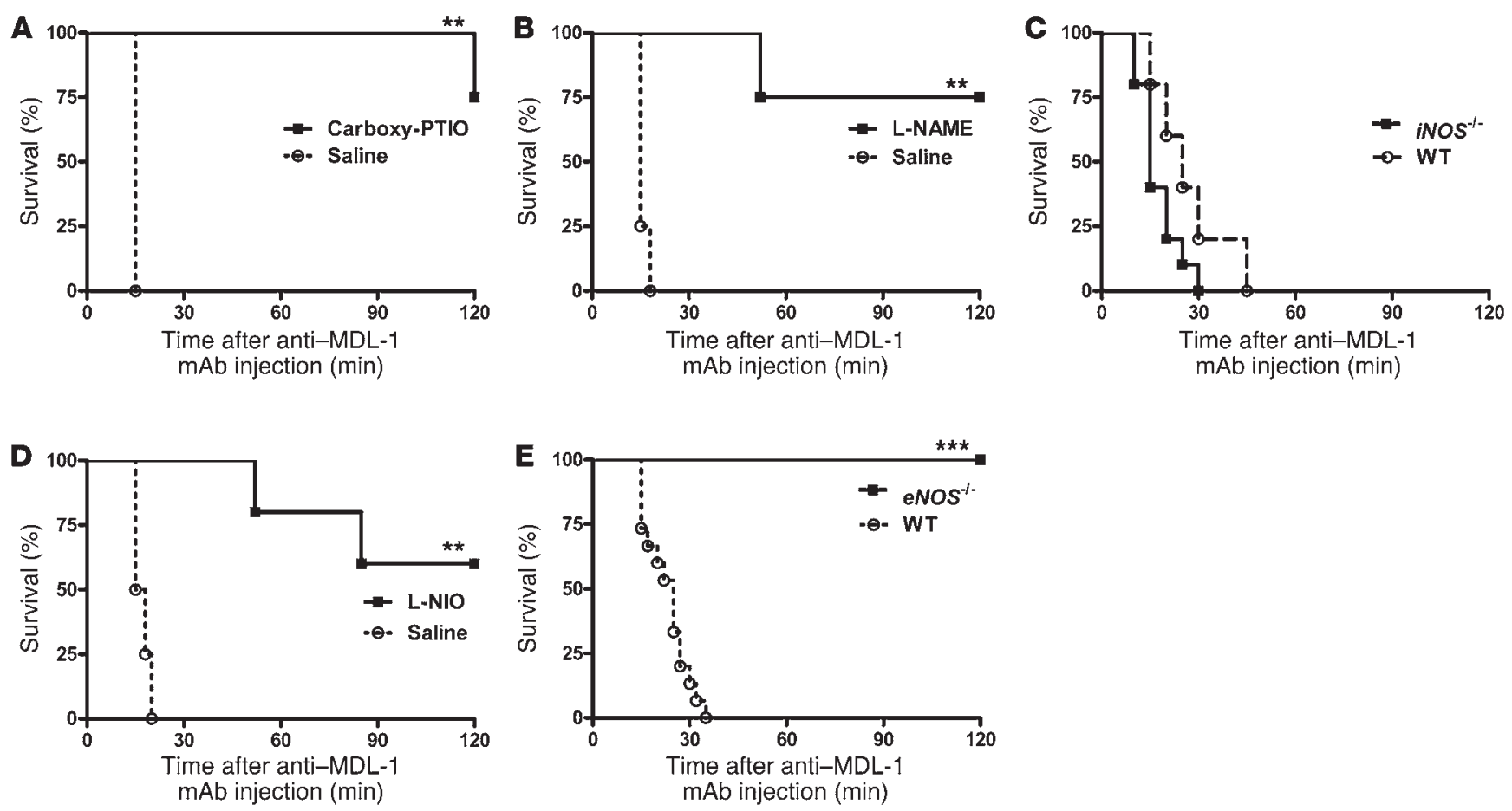

Figure 6

NO generated by eNOS is a critical mediator of MDL-1-induced shock. (A and B) Mice were administered ConA and pretreated with (A) NO scavenger (Carboxy-PTIO) or (B) NOS inhibitor (L-NAME) and control vehicle (saline) $(n=4)$ prior to stimulation with anti-MDL-1 mAb, and survival was monitored. ${ }^{* *} P<0.01$ compared with saline. (C) WT or iNOS $^{-/-}$mice $(n=10)$ were treated with ConA, followed by anti-MDL-1 mAb, and survival was monitored. (D) Mice were administered ConA and pretreated with eNOS inhibitor (L-NIO) $(n=5)$ or vehicle (saline) $(n=4)$ prior to stimulation with anti-MDL-1 mAb, and survival was monitored. ${ }^{*} P<0.01$ compared with saline. (E) WT or eNOS ${ }^{-1-}$ mice $(n=10)$ were treated with ConA, followed by anti-MDL-1 mAb, and survival was monitored. ${ }^{* *} P<0.001$ compared with WT.

Activation of DAP12, DAP10, Syk, PI3K, and Akt is important for $M D L-1-m e d i a t e d ~ s h o c k$. We set out to define the downstream signaling pathway of MDL-1 that plays a role in MDL-1-triggered shock. MDL-1 has been reported to associate with adaptor protein DAP12 to generate signals (9). As expected, DAP12-deficient animals were resistant to lethal shock induced by MDL-1 (Figure 8A). Another adaptor protein, DAP10, has recently been reported to associate with MDL-1 in osteoclasts and to modulate bone remodeling in concert with DAP12 (30). As shown in Figure 8B, DAP10-/- mice were also protected, indicating that both DAP12 and DAP10 are important for lethal shock triggered by MDL-1.

In NK cells, stimulation of DAP12 and DAP10 leads to association and activation of the downstream protein kinase Syk (31, 32 ) and PI3K (33), respectively. To investigate the role of these two kinases on MDL-1-induced shock, we pretreated mice with inhibitors specific for Syk (BAY 61-3606) and PI3K (wortmannin) prior to initiation of shock. Blockade of Syk or PI3K resulted in complete protection from shock compared with pretreatment with control vehicle (Figure 8, C and D). Since Akt is an immediate downstream target of PI3K and has been shown to activate eNOS $(34,35)$, we asked whether blocking Akt would provide any protective effect. Pretreatment of mice with Akt inhibitor MK-2206 $(36,37)$ led to a significantly higher survival rate compared with pretreatment with control vehicle (Figure 8E).

To further delineate the signaling mechanism involved in this MDL-1-mediated eNOS activation pathway that is critical for lethal shock, we stimulated $\mathrm{CD} 11 \mathrm{~b}^{+}$cells with anti-mouse
MDL-1 mAb and detected eNOS phosphorylation by immunoblotting. As shown in Figure 8F, there was an increase in phosphorylation of eNOS ( $\mathrm{p}$-eNOS) in MDL-1-stimulated cells relative to control, while the total eNOS protein immunoprecipitated was comparable. Since Akt, the downstream target of PI3K, has previously been shown to directly phosphorylate and activate eNOS, resulting in NO production (34), membranes were stripped and reprobed to detect phosphorylated and total Akt. Akt phosphorylation was enhanced in response to MDL-1 stimulation, with an equal amount of total Akt detected. These data also demonstrated a direct physical interaction between the Akt and eNOS activated by MDL-1. The formation of this signaling complex is independent of MDL-1 activation, as the level of total eNOS and Akt detected was similar in control and MDL-1-stimulated cells. Our results clearly define the signaling pathway downstream of MDL-1, including activation of adaptor proteins DAP12 and DAP10, as well as kinases Syk, PI3K, and Akt, as critical for MDL-1-mediated lethal shock (as modeled in Figure 9).

\section{Discussion}

Based on our observation of the recruitment of MDL-1+ leukocytes following ConA-induced liver injury and the report that DV binds and activates MDL-1 (6), we set out to delineate the cellular and molecular mechanisms underlying the progression from tissue injury/SIRS to shock. In order to specifically isolate the MDL-1-mediated effects rather than those associated with a more complex infectious process, we employed inactivated DV and, even 


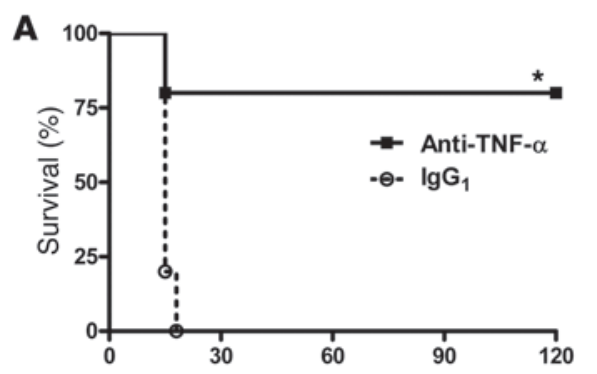

Time after anti-MDL-1 mAb injection (min)
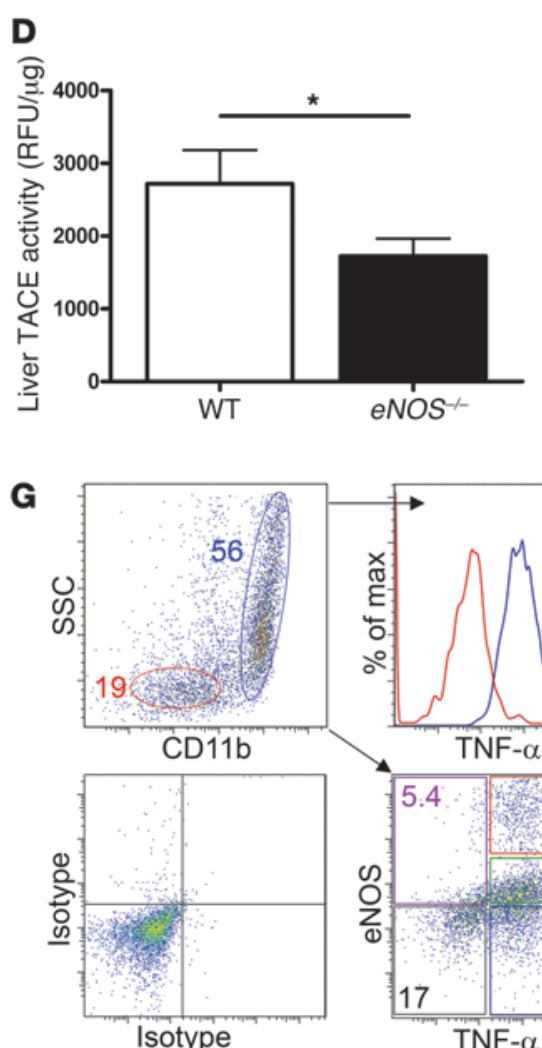

Isotype

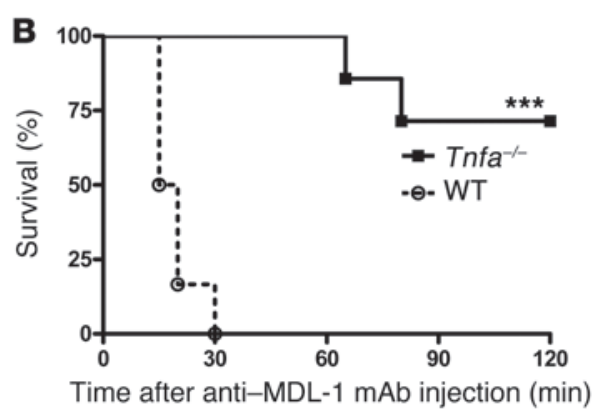

$\mathbf{E}$

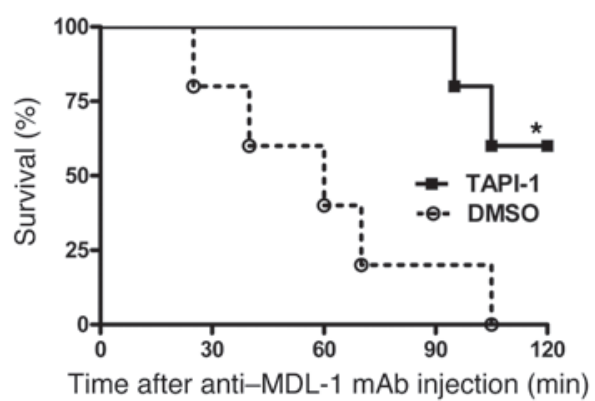

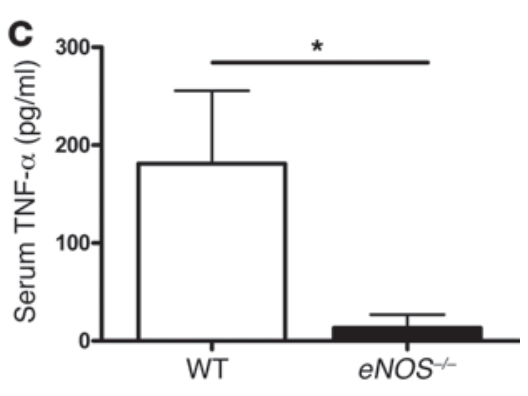

$\mathbf{F}$

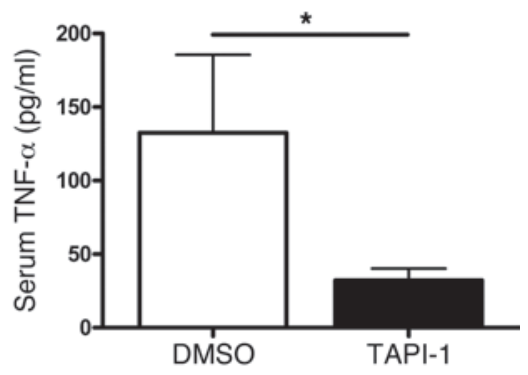

Figure 7

TNF- $\alpha$ is an important mediator of MDL-1-induced shock and is modulated by eNOS via regulating TACE activity. (A) Mice were pretreated with TNF- $\alpha$ neutralizing $\mathrm{mAb}$ or $\operatorname{lgG}_{1}(n=5)$ prior to administration of ConA, followed by anti-MDL- $1 \mathrm{mAb}$, and survival was monitored. ${ }^{*} P<0.05$ compared with $\operatorname{lgG}_{1}$. (B) WT or Tnfa- mice $(n=7)$ were treated with ConA, followed by anti-MDL-1 mAb, and survival was monitored. ${ }^{* \star \star} P<0.001$ compared with WT. (C and D) Blood and livers were collected from WT or eNOS ${ }^{-1-}$ mice $(n=10)$ treated with ConA, followed by anti-MDL-1 mAb, as in Figure 6E, and (C) serum TNF- $\alpha$ levels and (D) hepatic TACE activity were measured. ${ }^{*} P<0.05$ compared with WT. (E) Mice were treated with ConA and TAPI-1 $(n=5)$, followed by anti-MDL-1 mAb, and survival was monitored. ${ }^{*} P<0.05$ compared with DMSO. (F) Blood collected from the mice represented in $\mathbf{E}$ was measured for serum TNF- $\alpha .{ }^{*} P<0.05$ compared with DMSO. (G) Leukocytes isolated from livers of ConA-treated mice were analyzed by flow cytometry for expression of TNF- $\alpha$, eNOS, and MDL-1 gated on CD11 b+ cells. Background signal was established in

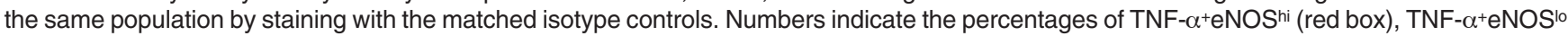
(green box), TNF- $\alpha^{+} e N^{-} S^{-}$(blue box), TNF- $\alpha^{-} \mathrm{eNOS}^{+}$(purple box), and TNF- $\alpha^{-} \mathrm{eNOS}^{-}$(black box) cell populations. The individual population was analyzed for MDL-1 expression (dotted line indicates isotype control).

more specifically, an agonist anti-MDL-1 antibody, to remove the effects of DV particles binding to other known binding partners such as DC-SIGN $(6,38,39)$. Thus, our experimental system does not represent a model of DV infection but instead functions to specifically address the contribution of MDL- 1 signaling in the progression from liver injury to shock. Using this system, we found that ConA-induced liver injury drives a hepatic infiltration of MDL-1+ immature myeloid cells of the granulocyte lineage and that triggering of MDL-1 on these cells, either by inactivated DV or an agonist antibody, results in lethal shock. An increase in circulating immature neutrophils ("left shift") is a common component of the clinical syndrome of SIRS/sepsis. This work suggests that, in the appropriate context such as liver injury, these immature neutrophils may contribute to the pathogenesis of shock. 

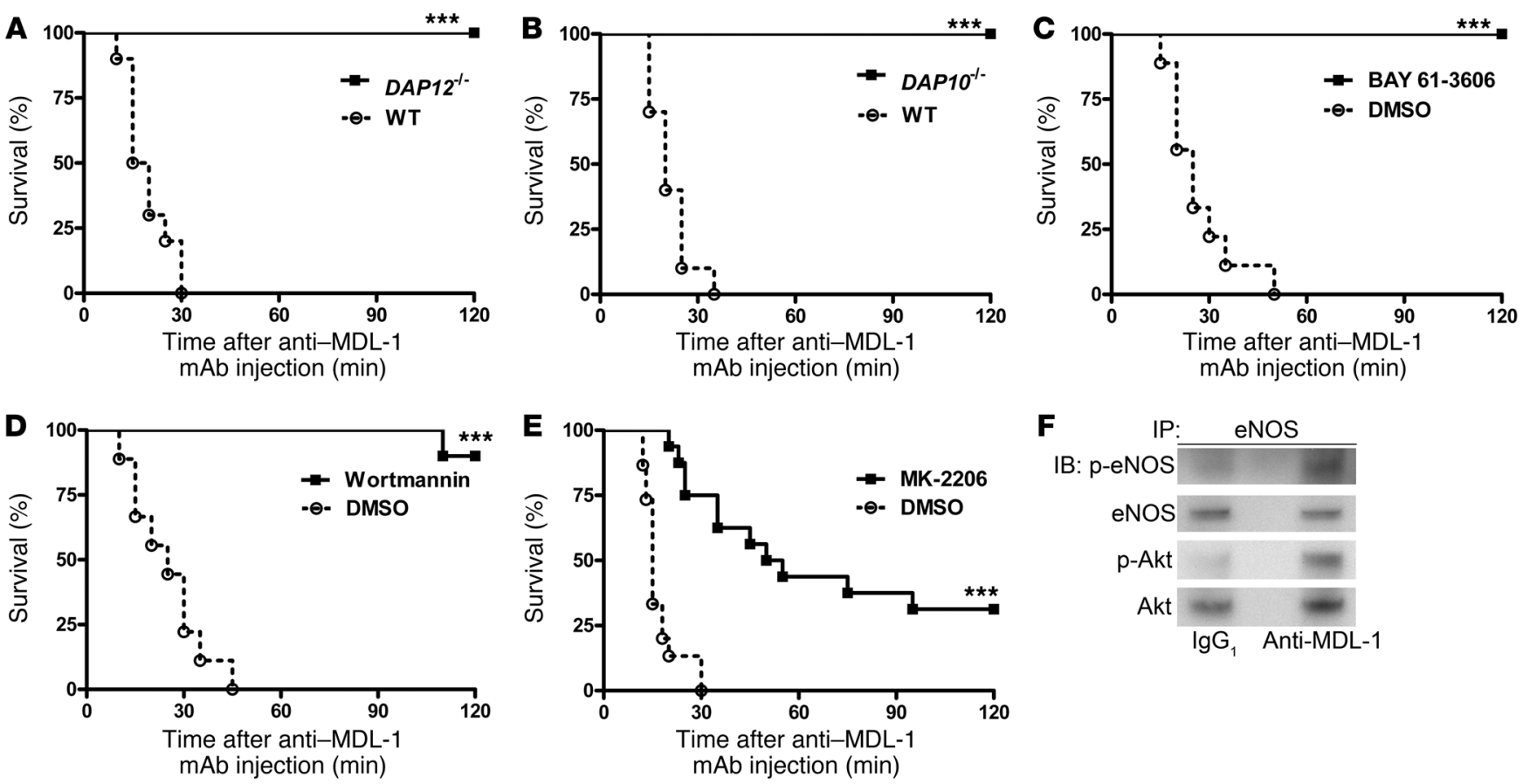

Figure 8

Blockade of DAP12, DAP10, Syk, PI3K, and Akt confers protection from MDL-1-triggered shock. (A and B) WT and (A) DAP12-/- or (B) $D A P 10^{-/-}$mice $(n=5)$ were treated with ConA, followed by anti-mMDL-1 mAb, and survival was monitored. ${ }^{* * *} P<0.001 \mathrm{compared}$ with WT. (C-E) Mice were administered with ConA and pretreated with inhibitors for (C) Syk (BAY 61-3606) $(n=4)$ or (D) PI3K (wortmannin) ( $n=5$ ), (E) Akt (MK-2206) $(n=16)$ or vehicle (DMSO) prior to stimulation with anti-mMDL-1 mAb, and survival was monitored. ${ }^{* * *} P<0.001 \mathrm{compared}$ with vehicle control. (F) MDL-1 activates Akt and eNOS to form a signaling complex. Leukocytes isolated from livers of ConA-treated mice were stimulated with anti-MDL-1 mAb or IgG 1 , and cell lysates were immunoprecipitated with anti-eNOS and immunoblotted with antibodies against phosphorylated eNOS(Ser1177) (p-eNOS), eNOS, phosphorylated Akt(Ser473) (p-Akt), and Akt. Data are representative of 2-3 independent experiments with at least 3 mice per group.

In our model, in the absence of ConA treatment, very few MDL- $1^{+}$ cells were detected in the liver (Figure 1B) and administration of DV or agonist $\mathrm{mAb}$ caused no overt response (data not shown). This fact highlights the importance of ConA-induced liver injury for the recruitment of immature myeloid cells. This is in agreement with two recent studies reporting that liver inflammation induced by high-fat diet or Th1 cells may drive the accumulation of immature myeloid cells in the liver $(40,41)$. The precise role of these infiltrating immature myeloid cells is not clear, as they have been reported to have a proinflammatory or antiinflammatory response. Interestingly, mice treated with ConA for 4 hours showed a modest, 1.5-fold increase in serum ALT (Supplemental Figure 3A, bottom panel), suggesting that only minor liver injury is sufficient to trigger the recruitment of these immature myeloid cells.

ConA-induced hepatic injury closely resembles the pathophysiology of T cell-mediated liver diseases; it therefore has been used extensively as an animal model for autoimmune and viral hepatitis $(12,42)$. DV-infected mice showed significant liver damage, which also correlated with $T$ cell activation and hepatic cellular infiltrate (43). This is concordant with clinical data showing that in general more than $80 \%$ of dengue patients had elevated serum levels of liver enzymes (ALT, AST), and the mean levels of these enzymes were significantly higher in patients with DSS as compared with DF (44). Dengue patients also displayed increased lymphocyte infiltration to the portal track $(45,46)$. We therefore believe that ConA-induced, T cell-mediated hepatitis is a valid model for virus-induced liver injury.
IFN- $\gamma$, TNF- $\alpha$, IL- $1 \beta$, IL- 6 , and G-CSF have previously been reported to be elevated in serum of DV-infected patients $(47,48)$. We found that ConA treatment also elevated serum levels of these proinflammatory molecules; and we were able to recapitulate the ConA effect by treating mice with recombinant G-CSF to recruit the MDL- $1^{+}$ cells, as well as a low dose of IFN- $\gamma$, TNF- $\alpha$, IL-1 $1 \beta$, and IL- 6 to prime the pathogenic cells. Subsequent triggering by DV or agonist mAb resulted in mice dying of shock, mediated primarily by MDL-1 activation and not due to cytokine priming. Therefore, results from this in vivo reconstitution experiment may provide further insight into the important role these cytokines play in the recruitment and priming of the MDL- $1^{+}$pathogenic cells during DV infection.

Given the profound sensitizing effect of ConA-induced liver injury on MDL-1-mediated shock, we asked whether this effect is unique to ConA or if liver injury in general would trigger infiltration of these immature myeloid cells and sensitize mice to shock. To address this question, we used the APAP-induced liver injury model, since APAP overdose is currently the most frequent cause of acute liver failure in both the United States and the United Kingdom $(49,50)$ and thus has significant clinical implications. Although APAP treatment caused both liver injury and hepatic infiltration of MDL- $1^{+}$cells in a time-dependent manner, MDL-1 stimulation at the time of maximal recruitment failed to cause death. One possible explanation is that insufficient numbers of pathogenic cells were recruited to the liver, as there were 7 -fold fewer MDL- $1^{+}$cells after APAP- versus ConA-induced injury. This rela- 


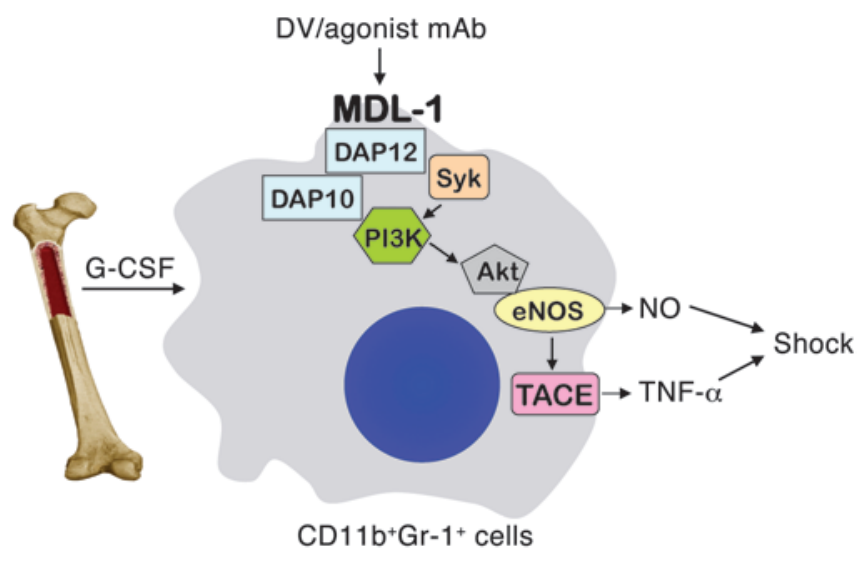

Figure 9

A proposed model for signaling mechanisms of MDL-1-mediated shock. Binding of MDL-1 by DV or anti-MDL-1 agonist mAb on CD11b+Gr-1+ immature myeloid cells triggers activation of adaptor proteins DAP12 and DAP10, as well as the downstream kinases Syk, $\mathrm{PI} 3 \mathrm{~K}$, and Akt. Akt physically interacts with and phosphorylates eNOS to produce NO. NO in turn triggers TNF- $\alpha$ production, at least in part by increasing TACE activity. Both NO and TNF- $\alpha$ are important mediators for MDL-1-mediated lethal shock.

tive inability of APAP-induced injury to mobilize MDL- $1^{+}$cells can be attributed to the fact that there is significantly less G-CSF being released in response to the injury. In addition to the deficit in the recruitment of MDL-1 ${ }^{+}$cells, APAP-induced liver injury also generated markedly fewer inflammatory cytokines, including IFN- $\gamma$, TNF- $\alpha$, IL-1 $\beta$, and IL- 6 , which we have shown to be critical for cell priming. These findings are not entirely surprising, considering the very different mechanisms of action for liver injury induced by APAP (toxic metabolite-mediated) and ConA ( $\mathrm{T}$ cell-mediated), which have been discussed in previous publications $(51,52)$. Fitting with our mouse model data, early epidemiological studies reported that APAP-induced liver damage had no potentiating effect on the DV-induced disease outcome in humans $(53,54)$.

Our observation that liver injury induced by both ConA and APAP is capable of triggering hepatic infiltration of MDL- $1^{+}$cells, albeit with different efficiencies, led us to hypothesize that the association between liver injury and development of DSS may be attributed to the recruitment of pathogenic cells. Increased numbers of immature neutrophils in the blood of DSS patients have been reported $(55,56)$; it would be of great interest to see whether these patients also have elevated liver enzyme levels in the blood.

Based on cell surface markers and morphology $(19,57)$, we have identified the pathogenic cells responsible for MDL-1-mediated lethal shock as immature myeloid cells. These cells also expressed the myeloid precursor marker CD33 $(20,21)$ and MHC class I, but not hematopoietic stem cell/progenitor cell marker CD34 (58) or $\mathrm{MHC}$ class II. This unique phenotype of $\mathrm{CD} 33^{+} \mathrm{CD} 34^{-} \mathrm{MHC}$ class $\mathrm{I}^{+}$class $\mathrm{II}^{-}$is consistent with that of promyelocytes (59-62). We also observed strong G-CSFR staining on MDL-1+ cells, which is in accordance with two previous studies reporting that G-CSFR is highly expressed on $\mathrm{CD} 33^{+} \mathrm{CD} 34^{-}$human bone marrow cells $(63,64)$ and provides further evidence that the MDL-1-expressing pathogenic cells are immature myeloid cells/promyelocytes. This is in agreement with clinical data showing an increased number of immature leukocytes in the blood of patients dur- ing DSS or septic shock $(55,56)$ and the detection of MDL- $1^{+}$ cells in the spleen of septic patients (65). In mice, CD $11 \mathrm{~b}^{+} \mathrm{Gr}-1^{+}$ immature myeloid cells are also expanded in the spleen during sepsis (66). CD $11 \mathrm{~b}^{+} \mathrm{Gr}-1^{+}$immature myeloid cells can be further characterized, based on cell surface markers Ly6G and Ly6C, into granulocytic $\left(\mathrm{CD} 11 \mathrm{~b}^{+} \mathrm{Ly} 6 \mathrm{G}^{+} \mathrm{Ly} 6 \mathrm{C}^{\mathrm{lo}}\right)(67,68)$ and monocytic (CD11 b ${ }^{+}$Ly6G-Ly6Chi) (40) populations. The immature myeloid cells expanded in our model were primarily granulocytic, and they expressed higher levels of MDL-1 than the smaller monocytic population. Interestingly, the $\mathrm{Ly} 6 \mathrm{G}^{+} \mathrm{Ly} 6 \mathrm{C}^{\text {lo }}$ granulocytic subset of the $\mathrm{CD} 11 \mathrm{~b}^{+} \mathrm{Gr}-1^{+}$cells is also the predominant population expanded in tumor-bearing mice (69).

Immature myeloid cells have been reported to be mobilized from bone marrow into peripheral blood primarily by G-CSF (70-74), which corroborates our finding that G-CSF, but not GM-CSF, KC, MIP-2, or MCP-1, acts as a critical proinflammatory molecule in MDL-1-induced shock by promoting the mobilization (and possibly the generation, egression, and maturation) of the pathogenic cells to the liver. In addition to the liver, these ring cells are also found in peripheral blood in response to ConA treatment (Supplemental Figure 7A), supporting the notion that immature myeloid cells egress from the bone marrow into the circulatory system in response to inflammation. We also asked whether MDL-1 itself is involved in myeloid cell migration by comparing the number of ring cells in WT and $M D L-1^{-1-}$ mice treated with ConA. We observed similar ConA-induced migration of immature myeloid cells, in both Cytospin preparation and IHC staining, between WT and $M D L-1^{-1-}$ mice (Supplemental Figure 7, A-D). Therefore, we concluded that ConA drives the recruitment of immature myeloid cells independent of MDL-1 and that the protection demonstrated in $M D L-1^{-/-}$mice is not due to impaired hepatic migration of the pathogenic cells.

Overproduction of NO is known to be an important factor in the pathogenesis of shock of various etiologies in humans. Compared with healthy individuals, patients with septic or anaphylactic shock have an elevated NO level in blood or exhaled air, respectively $(75,76)$. In addition, DSS patients have significantly higher serum NO than patients with DHF (77). It is generally believed that during the early stage of shock, there is a transient release of low levels (nanomoles) of NO produced by eNOS, which is constitutively expressed primarily in endothelial cells and is activated by an increase in intracellular calcium. This is followed by sustained local production of a large quantity (micromoles) of NO via calcium-independent $i N O S$ gene induction in immune cells, including macrophages, in response to immunological stimuli such as inflammatory cytokine production. The iNOS-mediated overproduction of NO is assumed to be responsible for the cardiovascular failure and mortality associated with different kinds of shock. However, results from our study clearly indicated that eNOS is the primary enzyme responsible for lethal shock triggered by MDL-1 and the associated increase in serum NO. This may seem surprising, although it is not without precedent: our results are consistent with a recent study showing the exclusive role eNOS plays in anaphylactic shock (78), as well as two reports implicating constitutive eNOS in septic and hemorrhagic shock $(79,80)$.

Although eNOS has originally been thought to be expressed primarily in endothelial cells, increasing evidence is revealing a much broader expression spectrum in leukocytes than previously thought. eNOS is also expressed in both mouse and human neutrophils, monocytes, and macrophages, as well as in human immature myeloid cells (81-87). In the mouse model, on the other 
hand, the production of NO by CD $11 \mathrm{~b}^{+} \mathrm{Gr}-1^{+}$immature myeloid cells has only been reported to be mediated by iNOS $(67,88)$. Our study is the first to our knowledge to identify a unique population of NO-producing murine immature myeloid cells expressing only eNOS, as we demonstrated that these cells are iNOS ${ }^{-}$and that ConA treatment induces a time-dependent upregulation of eNOS mRNA in the liver, whereas $i N O S$ transcript is undetectable (data not shown). The predominant role of eNOS in immature myeloid cells that we report is in agreement with a recent publication showing high eNOS expression in immature rat neutrophils, which is downregulated with maturation (89). Our results showing that these eNOS-expressing immature myeloid cells are also MDL- $1^{+}$ and are capable of producing NO with MDL-1 stimulation in vitro suggest a one-cell model scenario. The pathogenicity conferred by passive transfer and the protection achieved after in vivo depletion further highlight the importance of these cells. However, at this point we cannot eliminate the possibility of a two-cell model in which MDL-1-activated immature myeloid cells produce intermediate mediator(s) to stimulate endothelial cells to generate NO.

TNF- $\alpha$ has also been implicated as a crucial mediator for shock of different etiologies. In clinical data, elevated TNF- $\alpha$ levels were reported in blood of patients with septic, hemorrhagic, and anaphylactic shock (90-92). High levels of TNF- $\alpha$ were also observed in sera of all patients with dengue infection, with the highest values found in patients with DSS (93). Furthermore, the elevation of TNF- $\alpha$ in the serum has been reported to be strongly associated with clinical disease progression from DF to DSS $(94,95)$. Furthermore, anti-TNF- $\alpha$ antibody has been reported to be an effective treatment to reduce mortality associated with DV infection (96). Previously, macrophages were reported to be the primary cell type expressing MDL-1 that DV interacts with to trigger TNF- $\alpha$ release (6). The present study identifies immature myeloid cells as another MDL-1-expressing cell capable of releasing the inflammatory cytokine TNF- $\alpha$ in response to DV stimulation and playing a crucial role in DV-mediated pathobiology. Future studies measuring MDL-1 expression on the immature neutrophils that are increased in the blood of patients with DSS or septic shock, and the ability of these cells to produce TNF- $\alpha$ in response to MDL- 1 stimuli, are expected to further establish the clinical relevance of these cells in shock. Our results showing that MDL- $1^{+}$cells expressed both eNOS and TNF- $\alpha$ led us to investigate the cross-regulation of these two mediators. In our MDL-1-mediated pathway, eNOS is upstream of TNF- $\alpha$ and is able to regulate TNF- $\alpha$ production by modulating TACE activity. This result fits into the paradigm of a previous study showing that NO activates TACE by nitrosation of the inhibitory cysteine switch motif in the TACE prodomain and cleaving the membrane-bound TNF- $\alpha$ (29). In addition to binding its cognate receptor to induce an inflammatory response, TNF- $\alpha$ can activate eNOS activity via an Akt-dependent pathway to initiate an amplification process $(97,98)$. TNF- $\alpha$ is also able to terminate or dampen the signal by downregulating eNOS mRNA by shortening its halflife as a negative feedback mechanism (99). Although the hypothesis has not been proven, it is likely that this complex network of interplay between NO and TNF- $\alpha$ is part of the MDL-1-mediated pathway to fine-tune the biological response.

In addition to $\mathrm{NO}$ and TNF- $\alpha$, we also observed elevated levels of multiple cytokines (IFN- $\gamma$, IL-1 $\beta$, IL-6, IL-10) and chemokines (MCP-1, MIP-1 $\alpha$, IP-10) in the serum of mice that died of MDL-1mediated shock (Supplemental Figure 8). This is in accordance with the results of 6 separate dengue patient studies done in Brazil, Cuba,
India, Singapore, Thailand, and Vietnam that all showed increases in IFN- $\gamma$, IL-1 $\beta$, IL-6, IL-10, MCP-1, MIP- $1 \alpha$, and IP-10 in the serum (48, 100-104). These data support the idea that a "cytokine storm" is involved in the pathogenesis of DSS (105). It also demonstrates that our MDL-1-mediated shock model resembles the cytokine profile observed in DV-induced human disease. However, the contribution of each individual cytokine or chemokine to the pathogenesis of DSS, and the role MDL-1 plays in modulating these mediators, are well beyond the scope of this study but will warrant separate detailed investigation in the future.

The MDL-1-mediated signaling pathway is not clearly defined. Current understanding of signaling events downstream of DAP12 and DAP10 are primarily based on in vitro data obtained by triggering of receptor TREM-1 and NKG2D, respectively $(106,107)$. Therefore, we decided to use both genetic knockout mice and biochemical inhibitors to interfere with the signaling pathways in vivo to identify the MDL-1-specific downstream signaling events that are relevant to this disease model. Our results strongly indicated that activation of both adaptor protein DAP12 and DAP10, as well as the protein kinase Syk, PI3K, and Akt, are critical for MDL-1induced shock. Our results showing an absolute requirement for both DAP10 and DAP12 signaling is somewhat surprising, given that previous studies in NK cells have demonstrated at least partial redundancy between these two adaptor molecules $(108,109)$. However, it appears that the relative contribution of the two adaptor molecules to the downstream function is highly dependent on the examined receptor and cellular function. This requirement for signals generated from both adaptor molecules may also indicate that a critical "threshold" of signal, possibly at the level of PI3K (110), has to be reached to trigger shock. This hypothesis is supported by a recent study showing that both DAP10 and DAP12 are required for maximal TREM2-stimulated PI3K activity, with DAP10 mediating the recruitment of PI3K to DAP12 and the activation of downstream kinase Akt (111). In our model of MDL-1induced shock, DAP10 may be similarly responsible for amplifying DAP12-mediated PI3K activation, leading to a pathogenic activation of the downstream Akt/eNOS signaling response.

This is the first report to our knowledge to establish eNOS as a target of MDL-1, the triggering of this receptor resulting in eNOS activation and NO release, which in turn modulates another downstream cytokine, TNF- $\alpha$. It has been suggested that an increase in intracellular calcium alone is not sufficient to affect the enzymatic activity of eNOS and that protein phosphorylation is also critical in regulating eNOS function (112). Since Akt-mediated eNOS phosphorylation has been shown to play an important role in anaphylactic shock (78), we asked whether activation of MDL-1 can stimulate Akt to phosphorylate eNOS. Our results indicated that (a) triggering of MDL-1 results in phosphorylation of Akt and eNOS, (b) transduction of MDL-1 signal requires physical interaction between the two proteins to form a signaling complex, and (c) complex formation is independent of MDL-1 activation. In endothelial cells, HSP90 has been suggested to function as a scaffold to facilitate the proximity of and association between Akt and eNOS (113-116). As it is likely that such a scaffolding protein is involved in MDL-1-mediated signal transduction in immature myeloid cells, this should be further investigated.

The mortality rate for shock is high, with statistics associated with septic shock and DSS approximately $50 \%$ and $44 \%$, respectively (117, 118). Volume replacement therapy is considered the only effective treatment to restore circulation. Several other treatment options 
have been tested and found not to be effective. Two clinical trials have been conducted using anti-TNF- $\alpha \mathrm{mAb}$ for the treatment of septic shock, but the results were inconclusive, as one study showed reduced mortality, while the subsequent trial revealed no significant improvement in survival $(119,120)$. Another clinical trial using NOS inhibitor monomethyl-L-arginine (L-NMMA) treatment for septic shock patients showed improved resolution of shock with reduction in serum NO levels and increased vascular tone $(121,122)$. Despite a positive outcome on blood pressure, a phase III clinical trial had to be prematurely terminated due to increased mortality (123). Given the prominent role eNOS played in anaphylactic shock and the newfound importance of this enzyme in shock triggered by MDL-1 revealed by our study, it is plausible that a selective eNOS inhibitor could be used as a new therapy. TACE inhibitor is currently being tested in a clinical trial for the treatment of rheumatoid arthritis (124). Our results showing that TAPI-1 treatment significantly prolongs the survival of MDL-1-triggered shock suggest the prospect of using TACE inhibitor as an alternative treatment for shock. Furthermore, our study indicates the crucial role that the PI3K/Akt pathway plays in lethal shock mediated by MDL-1, suggesting the application of PI3K/Akt inhibitors for DSS patients, in addition to their use in anticancer therapy (125).

Our study suggests that this mechanism may play an important role in the progression from tissue injury/SIRS to shock in a variety of clinical settings where mobilization of immature granulocytic myeloid cells occurs, especially in the case of dengue infection, where progression to DSS has been associated with ongoing liver damage and the viral particle itself has been shown to activate MDL-1. Given that inhibitors of many components of this signaling pathway (MDL-1, Syk, PI3K, and Akt) are being developed as potential drugs in other therapeutic areas, it will be interesting to assess whether this mechanism contributes to the progression to shock in patients and whether inhibition of this pathway has therapeutic value.

\section{Methods}

Mice. C57BL/6, $\mathrm{NOOS}^{-/}$, $\mathrm{iNOS}^{-/}$, and $\mathrm{CCR}^{-/-}$mice were purchased from The Jackson Laboratory. MDL-1 $1^{-/-}(10), D A P 12^{-/-}(126), D A P 10^{-/-}(127)$, and Tnfa ${ }^{-/}$ (128) mice were generated in-house. All knockout mice used were in a C57BL/6 background, and data were collected using female mice 6-10 weeks of age.

Reagents. ConA (Sigma-Aldrich) was diluted in saline and injected i.v. at a dose of $5 \mathrm{mg} / \mathrm{kg}$. Rat anti-mouse MDL-1 agonist mAb (clone DX163, $\mathrm{IgG}_{1}$, in-house) (10) or inactivated DV (type 2, Microbix) was injected i.p. at $0.5 \mathrm{mg} /$ mouse 4 hours after ConA. BAY 61-3606 (EMD Chemicals Inc., $10 \mathrm{mg} / \mathrm{kg}$ in 10\% DMSO), wortmannin (Sigma-Aldrich, $1.5 \mathrm{mg} / \mathrm{kg}$ in $1.5 \%$ DMSO), MK-2206 (Selleck Chemicals, $12.5 \mathrm{mg} / \mathrm{kg}$ in 5\% DMSO), carboxyPTIO (Tocris, $0.6 \mathrm{mg} / \mathrm{kg}$ in saline), L-NAME (EMD Chemicals, $30 \mathrm{mg} / \mathrm{kg}$ in saline), or L-NIO (Tocris, $20 \mathrm{mg} / \mathrm{kg}$ in saline) was administered i.p. 1 hour before anti-MDL-1 mAb. TAPI-1 (EMD Chemicals Inc., $75 \mathrm{mg} / \mathrm{kg}$ in DMSO) was injected i.p. immediately after ConA. Survival was monitored up to 2 hours after anti-MDL- 1 mAb or 24 hours after DV challenge.

APAP (Sigma-Aldrich) was diluted in PBS and injected i.p. at a dose of $500 \mathrm{mg} / \mathrm{kg}$ (16). Carrier- and endotoxin-free recombinant mouse cytokines were purchased from R\&D Systems and diluted in sterile saline solution. G-CSF was injected i.v. at a dose of $4 \mu \mathrm{g} /$ mouse 2.5 hours prior to MDL-1 activation. IFN- $\gamma$, TNF- $\alpha$, IL-1 $\beta$, and IL- 6 were injected i.p. at doses of 50, 10 , 2.5 , and $0.5 \mu \mathrm{g} /$ mouse, respectively, 0.5 hours after G-CSF administration.

In vivo and ex vivo bioluminescence imaging. To localized infiltration target of the inflamed cells, mice with shaved abdomen were anesthetized with isoflurane, injected i.p. with XenoLight Rediject Inflammation Probe (Caliper Life Sciences) at $200 \mathrm{mg} / \mathrm{kg} 4$ hours after ConA, and immediately imaged in an IVIS 200 Imaging System (Xenogen Corp.) for 5 minutes. Images were captured and analyzed with Living Image software version 2.6.2. Livers were removed from mice, incubated in inflammation probe for 1 minute, and imaged under the same conditions.

Quantitation of chemokines in mouse serum and livers. Blood and livers were isolated from mice treated with ConA for the indicated times. Serum was isolated from blood by centrifugation. Livers were weighed, homogenized in ice-cold PBS supplemented with protease inhibitor cocktail, and centrifuged at $14,000 \mathrm{~g}$ for 15 minutes at $4^{\circ} \mathrm{C}$. The supernatants were removed and kept at $-80^{\circ} \mathrm{C}$ until use. Chemokines (G-CSF, GM-CSF, KC, and MIP-2) in serum and liver homogenates were quantified by using a custom Milliplex Mouse Cytokine/Chemokine Immunoassay Kit (Millipore) according to the manufacturer's instructions. Data were acquired on a Luminex 100 System and analyzed by MasterPlex CT version 1.2.0.7 software (MiraiBio).

In vivo depletion of chemokines, cytokines, and cells. Rat anti-mouse neutralizing $\mathrm{mAbs}$ for G-CSF (clone 67604, IgG 1 ) or GM-CSF (clone MP122E9, $\operatorname{IgG}_{2 \mathrm{a}}$ ) were injected i.p. at doses of $0.25 \mathrm{mg} / \mathrm{mouse} 3$ or 2.5 hours, respectively, prior to ConA treatment. Rat anti-mouse neutralizing $\mathrm{mAbs}$ for $\mathrm{KC}$ (clone 48415, IgG 2 ) or MIP-2 (clone MAB452, IgG Ib $_{2}$ ) were injected i.p. at doses of $0.05 \mathrm{mg} / \mathrm{mouse} 1$ hour prior to ConA treatment. All neutralizing mAbs were from R\&D Systems. Rat anti-mouse TNF- $\alpha$ neutralizing mAb (clone MP6-XT22, IgG 1 , in-house) (129) was administered i.p. at doses of $0.5 \mathrm{mg} / \mathrm{mouse} 1$ hour prior to ConA treatment. Rat anti-mouse Gr-1 mAb (clone RB6-8C5, IgG2 , in-house) (130) was injected i.p. at doses of $0.1 \mathrm{mg} /$ mouse 24 hours prior to ConA treatment. All rat isotype controls ( $\operatorname{IgG}_{1}$ and $\mathrm{IgG}_{2 \mathrm{~b}}$ ) were generated in-house. Peripheral blood from mice was collected by tail bleed and analyzed on an Advia 120 hematology system (Bayer Corp.).

Immunohistochemistry. Livers were harvested immediately after death and either fixed in 10\% paraformaldehyde, then embedded in paraffin, or snap-frozen in OCT. Consecutive sections of $5-\mu \mathrm{m}$ thickness were cut and stained with $\mathrm{H} \& \mathrm{E}$.

Precision-cut liver slice preparation and culture. Livers were isolated from ConA-treated WT or $M D L-1^{-/-}$mice, 8-mm-diameter cores were obtained, and $250-\mu \mathrm{m}$-thick tissue slices were precision cut using a Brendel/Vitron tissue slicer (Vitron Inc.). Slices were incubated in oxygenated Aqix RS-1 solution supplemented with $2 \%$ FBS for 30 minutes before stimulation with anti-mouse MDL-1 agonist $\mathrm{mAb}$, isotype control $\mathrm{mAb}$, or $\mathrm{DV}$ at a final concentration of $10 \mu \mathrm{g} / \mathrm{ml}$ for the indicated time.

Cell isolation, flow cytometry, cytospin, cell culture, and adoptive transfer. Livers were removed from mice and cells were dissociated by gentleMACS Dissociator (Miltenyi Biotec) according to the manufacturer's protocol. CD45, $\mathrm{Gr}-1^{+}$, or $\mathrm{CD} 11 \mathrm{~b}^{+}$cell populations were enriched from mononuclear cells by antibody-conjugated microbeads, based on the manufacturer's instructions, and isolated cells were counted by a ViCell XR Analyzer (Beckman Coulter). For immunophenotyping, cells were labeled with fluorescent-conjugated rat antimouse CD45 (clone 30-F11, IgG 2 , eBioscience), CD11b (clone M1/70, IgG 2 , eBioscience), Gr-1 (clone RB6-8C5, IgG 2 b , eBioscience), Ly6G (clone 1A8, IgG 2 , BD Biosciences), Ly6C (clone AL-21, IgM, BD Biosciences), TNF- $\alpha$ (clone MP6XT22, IgG 1 , eBioscience), F4/80 (clone BM8, IgG ${ }_{2 a}$, eBioscience), MDL-1 (clone DX192, IgG 1 , in-house) mAbs, rabbit anti-human/mouse eNOS or iNOS (IgG, Santa Cruz Biotechnology Inc.) polyclonal Abs. For immunophenotyping of immature myeloid cells, cells were labeled with fluorescent-conjugated mouse anti-mouse MHC class I (H-2Kb) (clone AF6-88.5.5.3, IgG 2a $_{\text {a }}$ eBioscience), MHC class II (I-Ab) (clone AF6-120.1, IgG 2a , eBioscience), rat anti-mouse CD34 (clone RAM34, IgG 2 , BD Biosciences) mAbs, goat anti-mouse CD33 or rabbit anti-mouse G-CSFR (IgG, Santa Cruz Biotechnology Inc.) polyclonal Ab. For intracellular staining, cells were fixed (Cytofix, BD Biosciences - Pharmingen) and permeabilized (PhosFlow Perm III, BD Biosciences - Pharmingen) prior to staining. Data were acquired on a FACSCanto II flow cytometer (BD Biosciences) and analyzed by FlowJo version 7.6.1 software (TreeStar Inc.). 
The isolated cells were assessed morphologically on Cytospin slide preparations stained with Diff-Quik (Siemens Healthcare Diagnostics Inc.) according to the product instructions and visualized using an upright light transmission microscope (Olympus BX51) at $\times 40$ to $\times 100$ magnification. Representative images were captured using a QImaging Retiga-200R camera and analyzed with QCapture Pro 6.0 software (QImaging).

For immunocytochemistry, cells on Cytospin slides were stained with fluorescent-conjugated rat anti-mouse CD11b and MDL-1 mAbs and visualized with a Leica DM-RE fluorescence microscope at $\times 60$ magnification. Representative images were captured with a Photometrics CoolSNAP HQ camera (Roper Scientific) and analyzed using Image-Pro Plus 6.0 software (Media Cybernetics).

$\mathrm{CD}_{11} \mathrm{~b}^{+}$cells were resuspended in phenol red-free DMEM supplemented with $2 \%$ FBS and plated in 96-well plates at a density of $1 \times 10^{6} \mathrm{cells} / 100 \mu \mathrm{l}$ in triplicate or quadruplicate. The following day, cells were stimulated for 24 hours with anti-mouse MDL-1 agonist $\mathrm{mAb}$, isotype control $\mathrm{mAb}$, or $\mathrm{DV}$ at a final concentration of $10 \mu \mathrm{g} / \mathrm{ml}$. Cell culture media were collected and stored at $-80^{\circ} \mathrm{C}$ for determination of NO and TNF- $\alpha$ levels.

For adoptive transfer, $\mathrm{CD} 11 \mathrm{~b}^{+}$cells were washed, resuspended in PBS, and injected i.v. at $15 \times 10^{6}$ cells/naive mouse. Anti-mouse MDL- 1 agonist $\mathrm{mAb}$ or isotype control $\mathrm{mAb}$ was injected i.p. at $0.5 \mathrm{mg} /$ mouse 0.5 hours after transfer, and survival was monitored up to 16 hours after stimulation. Tissues and blood were collected immediately after death for IHC staining and for NO and TNF- $\alpha$ determination, respectively.

ELISA, Griess assay, and TACE activity assay. Conditioned media from liver slices or cell culture were collected at indicated times and spun at $10,000 \mathrm{~g}$ for 5 minutes to remove debris. G-CSF, TNF- $\alpha$, and NO levels in serum or culture media were measured by mouse G-CSF, TNF- $\alpha$ ELISA (Invitrogen), and Total Nitric Oxide Assay Kit (Pierce), respectively. Absorbance was measured using a Spectramax Plus 384 plate reader (Molecular Devices). TACE activity in liver homogenates was quantitated using a fluorometric assay with a SensoLyte 520 TACE Activity Assay Kit (AnaSpec Inc.) according to the manufacturer's instructions. The fluorescence intensity was measured in black micro-plates with a Modulus Microplate Multimode Reader (Turner BioSystems).

Quantitation of ALT, chemokines, and cytokines in mouse serum. Blood was isolated from mice treated with APAP or ConA for the indicated times, or from WT and $M D L-1^{-/}$mice treated with ConA and triggered with anti-MDL-1 mAb. Serum was isolated from blood by centrifugation. Serum ALT levels was measured by the Stanford University Diagnostic Laboratory. TNF- $\alpha$, IFN- $\gamma$, IL-1 $\beta$, IL-6, IL-10, MCP-1, IP-10, and MIP- $1 \alpha$ in serum were quantified by using Milliplex Mouse Cytokine/Chemokine Immunoassay Kit (Millipore).
Immunoprecipitation and immunoblot analysis. $\mathrm{CD} 11 \mathrm{~b}^{+}$cells were stimulated for 15 minutes with anti-mouse MDL- 1 agonist $\mathrm{mAb}$ or isotype control $\mathrm{mAb}$ at a final concentration of $10 \mu \mathrm{g} / \mathrm{ml}$ and solubilized in RIPA buffer containing protease and phosphatase inhibitors. Cell lysates $(400 \mu \mathrm{g})$ were incubated with $7.5 \mu \mathrm{g}$ anti-eNOS $\mathrm{mAb}$ (clone $3, \mathrm{IgG}_{1}, \mathrm{BD}$ Transduction Laboratories) for 3 hours at $4^{\circ} \mathrm{C}$. Protein $\mathrm{A} / \mathrm{G}$ beads were added and incubated overnight. Immunoprecipitates were washed three times with lysis buffer and boiled in Laemmli buffer. Cell lysates $(50 \mu \mathrm{g})$ were also boiled in sample buffer. Proteins were resolved by $4 \%-12 \%$ Bis-Tris NuPage gel and transferred to PVDF membranes. Conditions for blocking, washing, and dilution were based on instructions from antibody providers. To detect phosphorylation of eNOS and Akt, membranes were blocked with Tris-buffered saline with Tween 20 plus $5 \%$ BSA and incubated at $4{ }^{\circ} \mathrm{C}$ overnight with rabbit $\mathrm{mAb}$ for anti-phospho-eNOS (Ser1177) (clone C9C3 1:1,000, Cell Signaling Technology) or anti-phosphoAkt (Ser473) (clone D9E, 1:2,000, Cell Signaling Technology), respectively, followed by incubation with HRP-conjugated anti-rabbit secondary antibody for 1 hour. The signal was detected with ECL (GE Healthcare) and autoradiographic films. Membranes were stripped with Restore Western Blot Stripping Buffer (Pierce) and reprobed with rabbit polyclonal Ab for anti-eNOS (1:1,000, BD Biosciences) or anti-Akt (1:1,000, Cell Signaling Technology).

Statistics. Data are presented as mean \pm SEM. Statistical analysis was performed using Prism version 4.0 (GraphPad Software). Statistical significance was determined by 2-tailed Student's $t$ test for comparison of means and log-rank test to compare survival curves. $P$ values less than 0.05 were considered statistically significant.

Study approval. All animal procedures were approved by the IACUC of Merck.

\section{Acknowledgments}

The authors thank Barbara Joyce-Shaikh, Maria-Christina Malinao, Corinne Cayatte, Yamini Ohol, Christina Moon, Gil Asio, Patricia Bourne, and Scott Turner for assistance with the experiments and Drake Laface for helpful discussion.

Received for publication February 21, 2011, and accepted in revised form August 26, 2011.

Address correspondence to: Ricky Cheung or Robert H. Pierce, Merck Research Laboratories, 901 S. California Ave., Palo Alto, California 94304, USA. Phone: 650.496.1276; Fax: 650.496.1200; E-mail: ricky.cheung@utoronto.ca (R. Cheung). Phone: 650.496.6528; Fax: 650.496.1200; E-mail: robert.pierce@merck.com (R.H. Pierce).
1. Lotze MT, et al. The grateful dead: damage-associated molecular pattern molecules and reduction/oxidation regulate immunity. Immunol Rev. 2007;220:60-81.

2. Shpektor A. Cardiogenic shock: the role of inflammation. Acute Card Care. 2010;12(4):115-118.

3. Kalayanarooj S, et al. Early clinical and laboratory indicators of acute dengue illness. J Infect Dis. 1997;176(2):313-321.

4. Krishnamurti C, et al. Mechanisms of hemorrhage in dengue without circulatory collapse. Am J Trop Med Hyg. 2001;65(6):840-847.

5. Tee HP, et al. Risk factors associated with development of dengue haemorrhagic fever or dengue shock syndrome in adults in Hospital Tengku Ampuan Afzan Kuantan. Med J Malaysia. 2009;64(4):316-320.

6. Chen ST, et al. CLEC5A is critical for dengue-virus-induced lethal disease. Nature. 2008; 453(7195):672-676.

7. Gomes AL, et al. Classification of dengue fever patients based on gene expression data using support vector machines. PLoS One. 2010;5(6):e11267.
8. Noble CG, et al. Strategies for development of Dengue virus inhibitors. Antiviral Res. 2010;85(3):450-462.

9. Bakker AB, Baker E, Sutherland GR, Phillips JH, Lanier LL. Myeloid DAP12-associating lectin (MDL)-1 is a cell surface receptor involved in the activation of myeloid cells. Proc Natl Acad Sci U S A 1999;96(17):9792-9796.

10. Joyce-Shaikh B, et al. Myeloid DAP12-associating lectin (MDL)-1 regulates synovial inflammation and bone erosion associated with autoimmune arthritis. J Exp Med. 2010;207(3):579-589.

11. Aoki N, et al. Expression and functional role of MDL-1 (CLEC5A) in mouse myeloid lineage cells. J Leukoc Biol. 2009;85(3):508-517.

12. Tiegs G, Hentschel J, Wendel A. A T cell-dependent experimental liver injury in mice inducible by concanavalin A. J Clin Invest. 1992;90(1):196-203.

13. Gross $S$, et al. Bioluminescence imaging of myeolperoxidase activity in vivo. Nat Med. 2009;15(4):455-461.

14. Tennenberg SD, Fey DE, Lieser MJ. Oxidative priming of neutrophils by interferon-gamma. J Lenkoc Biol. 1993;53(3):301-308.
15. Elbim C, Bailly S, Chollet-Martin S, Hakim J, Gougerot-Pocidalo MA. Differential priming effects of proinflammatory cytokines on human neutrophil oxidative burst in response to bacterial $\mathrm{N}$-formyl peptides. Infect Immun. 1994;62(6):2195-2201.

16. Imaeda AB, et al. Acetaminophen-induced hepatotoxicity in mice is dependent on Tlr 9 and the Nalp3 inflammasome. J Clin Invest. 2009;119(2):305-314.

17. Dong X, Swaminathan S, Bachman LA, Croatt AJ, Nath KA, Griffin MD. Resident dendritic cells are the predominant TNF-secreting cell in early renal ischemia-reperfusion injury. Kidney Int. 2007;71(7):619-628.

18. Fernekorn U, et al. Selectin, platelet plays a critical role in granulocyte access to the pregnant mouse uterus under physiological and pathological conditions. Biol Reprod. 2007;76(4):645-653.

19. Biermann H, Pietz B, Dreier R, Schmid KW, Sorg C, Sunderkotter C. Murine leukocytes with ringshaped nuclei include granulocytes, monocytes, and their precursors. J Lenkoc Biol. 1999;65(2):217-231.

20. Brinkman-Van der Linden EC, Angata T, Reynolds 
SA, Powell LD, Hedrick SM, Varki A. CD33/Siglec3 binding specificity, expression pattern, and consequences of gene deletion in mice. Mol Cell Biol. 2003;23(12):4199-4206.

21. Tchilian EZ, Beverley PC, Young BD, Watt SM. Molecular cloning of two isoforms of the murine homolog of the myeloid CD33 antigen. Blood. 1994;83(11):3188-3198.

22. MacNamara KC, et al. Infection-induced myelopoiesis during intracellular bacterial infection is critically dependent upon IFN-gamma signaling. J Immunol. 2011;186(2):1032-1043.

23. Landry DW, Oliver JA. The pathogenesis of vasodilatory shock. N Engl J Med. 2001;345(8):588-595.

24. Szabo C, Thiemermann C. Invited opinion: role of nitric oxide in hemorrhagic, traumatic, and anaphylactic shock and thermal injury. Shock. 1994;2(2):145-155.

25. Tracey KJ, et al. Shock and tissue injury induced by recombinant human cachectin. Science. 1986;234(4775):470-474

26. Beutler B, Cerami A. Cachectin/tumor necrosis factor: an endogenous mediator of shock and inflammation. Immunol Res. 1986;5(4):281-293.

27. Yoshida M, et al. Therapeutic effects of imidazolineoxyl $\mathrm{N}$-oxide against endotoxin shock through its direct nitric oxide-scavenging activity. Biochem Biophys Res Commun. 1994;202(2):923-930.

28. Jiang MH, Kaku T, Hada J, Hayashi Y. Different effects of eNOS and nNOS inhibition on transient forebrain ischemia. Brain Res. 2002;946(1):139-147.

29. Zhang $Z$, et al. Activation of tumor necrosis factor-alpha-converting enzyme-mediated ectodomain shedding by nitric oxide. J Biol Chem. 2000;275(21):15839-15844.

30. Inui M, et al. Signal adaptor DAP10 associates with MDL-1 and triggers osteoclastogenesis in cooperation with DAP12. Proc Natl Acad Sci U S A. 2009;106(12):4816-4821.

31. Lanier LL, Corliss BC, Wu J, Leong C, Phillips JH. Immunoreceptor DAP12 bearing a tyrosine-based activation motif is involved in activating NK cells. Nature. 1998;391(6668):703-707.

32. McVicar DW, et al. DAP12-mediated signal transduction in natural killer cells. A dominant role for the Syk protein-tyrosine kinase. J Biol Chem. 1998;273(49):32934-32942.

33. Wu J, Song Y, Bakker AB, Bauer S, Spies T, Lanier LL, Phillips JH. An activating immunoreceptor complex formed by NKG2D and DAP10. Science. 1999;285(5428):730-732.

34. Fulton D, et al. Regulation of endothelium-derived nitric oxide production by the protein kinase Akt. Nature. 1999;399(6736):597-601.

35. Dimmeler S, Fleming I, Fisslthaler B, Hermann C, Busse R, Zeiher AM. Activation of nitric oxide synthase in endothelial cells by Akt-dependent phosphorylation. Nature. 1999;399(6736):601-605.

36. Hirai H, et al. MK-2206, an allosteric Akt inhibitor, enhances antitumor efficacy by standard chemotherapeutic agents or molecular targeted drugs in vitro and in vivo. Mol Cancer Ther. 2010;9(7):1956-1967.

37. Meng J, et al. Combination treatment with MEK and AKT inhibitors is more effective than each drug alone in human non-small cell lung cancer in vitro and in vivo. PLoS One. 2010;5(11):e14124.

38. Tassaneetrithep B, et al. DC-SIGN (CD209) mediates dengue virus infection of human dendritic cells. J Exp Med. 2003;197(7):823-829.

39. Pokidysheva E, et al. Cryo-EM reconstruction of dengue virus in complex with the carbohydrate recognition domain of DC-SIGN. Cell. 2006; 124(3):485-493.

40. Deng ZB, et al. Immature myeloid cells induced by a high-fat diet contribute to liver inflammation. Hepatology. 2009;50(5):1412-1420.

41. Cripps JG, Wang J, Maria A, Blumenthal I, Gorham JD. Type $1 \mathrm{~T}$ helper cells induce the accumula- tion of myeloid-derived suppressor cells in the inflamed Tgfb1 knockout mouse liver. Hepatology. 2010;52(4):1350-1359.

42. Hegde VL, Hegde S, Cravatt BF, Hofseth LJ, Nagarkatti M, Nagarkatti PS. Attenuation of experimental autoimmune hepatitis by exogenous and endogenous cannabinoids: involvement of regulatory T cells. Mol Pharmacol. 2008;74(1):20-33.

43. Chen HC, et al. Lymphocyte activation and hepatic cellular infiltration in immunocompetent mice infected by dengue virus. J Med Virol. 2004;73(3):419-431.

44. Mohan B, Patwari AK, Anand VK. Hepatic dysfunction in childhood dengue infection.J Trop Pediatr. 2000;46(1):40-43.

45. Burke T. Dengue haemorrhagic fever: a pathological study. Trans R Soc Trop Med Hyg. 1968;62(5):682-692.

46. Kuo CH, Tai DI, Chang-Chien CS, Lan CK, Chiou SS, Liaw YF. Liver biochemical tests and dengue fever. Am J Trop Med Hyg. 1992;47(3):265-270.

47. Becquart $P$, et al. Acute dengue virus 2 infection in Gabonese patients is associated with an early innate immune response, including strong interferon alpha production. BMC Infect Dis. 2010;10:356.

48. Bozza FA, et al. Multiplex cytokine profile from dengue patients: MIP-1beta and IFN-gamma as predictive factors for severity. BMC Infect Dis. 2008;8:86.

49. Larson AM, et al. Acetaminophen-induced acute liver failure: results of a United States multicenter, prospective study. Hepatology. 2005;42(6):1364-1372.

50. Bernal W. Changing patterns of causation and the use of transplantation in the United kingdom. Semin Liver Dis. 2003;23(3):227-237.

51. Fushimi S, et al. Forced expression of suppressor of cytokine signaling 3 in T cells protects the development of concanavalin A-induced hepatitis in mice. Clin Immunol. 2009;133(3):437-446.

52. Masson MJ, et al. Pathologic role of stressedinduced glucocorticoids in drug-induced liver injury in mice. Biochem Biophys Res Commun. 2010;397(3):453-458.

53. Suvatte V, Vajaradul C, Laohapand T. Liver failure and hepatic encephalopathy in dengue hemorrhagic fever/dengue shock syndrome: a correlation study with acetaminophen usage. Southeast Asian J Trop Med Public Health. 1990;21:694-695.

54. Seneviratne SL, Malavige GN, de Silva HJ. Pathogenesis of liver involvement during dengue viral infections. Trans $R$ Soc Trop Med Hyg. 2006;100(7):608-614.

55. Liu CC, Huang KJ, Lin YS, Yeh TM, Liu HS, Lei HY. Transient CD4/CD8 ratio inversion and aberrant immune activation during dengue virus infection. JMed Virol. 2002;68(2):241-252.

56. Bone RC, et al. Definitions for sepsis and organ failure and guidelines for the use of innovative therapies in sepsis. The ACCP/SCCM Consensus Conference Committee. American College of Chest Physicians/Society of Critical Care Medicine. Chest. 1992;101(6):1644-1655

57. Kusmartsev S, Gabrilovich DI. Role of immature myeloid cells in mechanisms of immune evasion in cancer. Cancer Immunol Immunother. 2006; 55(3):237-245

58. Krause DS, et al. Characterization of murine CD34, a marker for hematopoietic progenitor and stem cells. Blood. 1994;84(3):691-701.

59. Cassinat B, Chomienne C. Biological features of primary APL blasts: their relevance to the understanding of granulopoiesis, leukemogenesis and patient management. Oncogene. 2001; 20(49):7154-7160

60. Scott AA, et al. HLA-DR-, CD33+, CD56+, CD16myeloid/natural killer cell acute leukemia: a previously unrecognized form of acute leukemia potentially misdiagnosed as French-American-British acute myeloid leukemia-M3. Blood. 1994;84(1):244-255.

61. Wall CD, et al. Expression of alpha IIb beta 3 inte- grin (GPIIb-IIIa) in myeloid cell lines and normal CD34+/CD33+ bone marrow cells. Blood Cells Mol Dis. 1997;23(3):361-376

62. Ochs RC, Gormley RH, Luger S, Bagg A. Isolated bowel relapse in acute promyelocytic leukemia: an unusual site of extramedullary recurrence. J Clin Oncol. 2010;28(29):e550-553.

63. Shinjo K, Takeshita A, Ohnishi K, Ohno R. Expression of granulocyte colony-stimulating factor receptor increases with differentiation in myeloid cells by a newly-devised quantitative flow-cytometric assay. Br J Haematol. 1995;91(4):783-794.

64. Shinjo K, Takeshita A, Ohnishi K, Ohno R. Granulocyte colony-stimulating factor receptor at various differentiation stages of normal and leukemic hematopoietic cells. Leuk Lymphoma. 1997; 25(1-2):37-46.

65. Cuenca AG, et al. A Paradoxical Role for MyeloidDerived Suppressor Cells in Sepsis and Trauma. Mol Med. 2011;17(3-4):281-292.

66. Delano MJ, et al. MyD88-dependent expansion of an immature GR-1(+)CD $11 \mathrm{~b}(+)$ population induces $T$ cell suppression and Th2 polarization in sepsis. J Exp Med. 2007;204(6):1463-1474.

67. Goni O, Alcaide P, Fresno M. Immunosuppression during acute Trypanosoma cruzi infection: involvement of Ly6G $(\mathrm{Gr} 1(+)) \mathrm{CD} 11 \mathrm{~b}(+)$ immature myeloid suppressor cells. Int Immunol. 2002; 14(10):1125-1134.

68. Yan $\mathrm{HH}$, et al. Gr-1+CD11b+ myeloid cells tip the balance of immune protection to tumor promotion in the premetastatic lung. Cancer Res. 2010; 70(15):6139-6149.

69. Youn JI, Nagaraj S, Collazo M, Gabrilovich DI. Subsets of myeloid-derived suppressor cells in tumorbearing mice. J Immunol. 2008;181(8):5791-5802.

70. Zhu QS, Xia L, Mills GB, Lowell CA, Touw IP, Corey SJ. G-CSF induced reactive oxygen species involves Lyn-PI3-kinase-Akt and contributes to myeloid cell growth. Blood. 2006;107(5):1847-1856.

71. Shojaei F, et al. Bv8 regulates myeloid-celldependent tumour angiogenesis. Nature. 2007; 450(7171):825-831.

72. Shojaei F, et al. G-CSF-initiated myeloid cell mobilization and angiogenesis mediate tumor refractoriness to anti-VEGF therapy in mouse models. Proc Natl Acad Sci U S A. 2009;106(16):6742-6747.

73. Joo YD, et al. Granulocyte colony-stimulating factor-induced immature myeloid cells inhibit acute graft-versus-host disease lethality through an indoleamine dioxygenase-independent mechanism. Immunology. 2009;128(1 suppl):e632-e640.

74. Zhang Y, et al. A novel function of granulocyte colony-stimulating factor in mobilization of human hematopoietic progenitor cells. Immunol Cell Biol. 2009;87(5):428-432.

75. Endo S, et al. Nitrite/nitrate oxide (NOx) and cytokine levels in patients with septic shock. Res Commun Mol Pathol Pharmacol. 1996;91(3):347-356.

76. Rolla G, Nebiolo F, Guida G, Heffler E, Bommarito L, Bergia R. Level of exhaled nitric oxide during human anaphylaxis. Ann Allergy Asthma Immunol. 2006;97(2):264-265.

77. Trairatvorakul P, Chongsrisawat V, Ngamvasinont D, Asawarachun D, Nantasook J, Poovorawan Y. Serum nitric oxide in children with dengue infection. Asian Pac J Allergy Immunol. 2005;23(2-3):115-119.

78. Cauwels A, Janssen B, Buys E, Sips P, Brouckaert P. Anaphylactic shock depends on PI3K and eNOSderived NO. J Clin Invest. 2006;116(8):2244-2251.

79. Szabo C, Mitchell JA, Thiemermann C, Vane JR. Nitric oxide-mediated hyporeactivity to noradrenaline precedes the induction of nitric oxide synthase in endotoxin shock. Br J Pharmacol. 1993;108(3):786-792.

80. Thiemermann C, Szabo C, Mitchell JA, Vane JR. Vascular hyporeactivity to vasoconstrictor agents and hemodynamic decompensation in hemor- 
rhagic shock is mediated by nitric oxide. Proc Natl Acad Sci U S A. 1993;90(1):267-271.

81. Zhao R, Guan DW, Lu B. [Immunohistochemical study on expression of iNOS and eNOS during skin incised wound healing in mice]. Fa Yi Xue Za Zhi. 2005;21(3):161-164.

82. Connelly L, Jacobs AT, Palacios-Callender M, Moncada S, Hobbs AJ. Macrophage endothelial nitric-oxide synthase autoregulates cellular activation and pro-inflammatory protein expression. J Biol Chem. 2003;278(29):26480-26487.

83. de Frutos T, et al. Expression of an endothelial-type nitric oxide synthase isoform in human neutrophils: modification by tumor necrosis factor-alpha and during acute myocardial infarction. J Am Coll Cardiol. 2001;37(3):800-807.

84. Reiling N, Ulmer AJ, Duchrow M, Ernst M, Flad HD, Hauschildt S. Nitric oxide synthase: mRNA expression of different isoforms in human monocytes/macrophages. Eur J Immunol. 1994;24(8):1941-1944.

85. Aubry JP, et al. The $25-\mathrm{kD}$ a soluble CD23 activates type III constitutive nitric oxide-synthase activity via CD11b and CD11c expressed by human monocytes. J Immunol. 1997;159(2):614-622.

86. van Straaten JF, Postma DS, Coers W, Noordhoek JA, Kauffman HF, Timens W. Macrophages in lung tissue from patients with pulmonary emphysema express both inducible and endothelial nitric oxide synthase. Mod Pathol. 1998;11(7):648-655.

87. Koistinen $\mathrm{P}$, et al. Regulation of the acute myeloid leukemia cell line OCI/AML-2 by endothelial nitric oxide synthase under the control of a vascular endothelial growth factor signaling system. Leukemia. 2001;15(9):1433-1441.

88. Angulo I, de las Heras FG, Garcia-Bustos JF, Gargallo D, Munoz-Fernandez MA, Fresno M. Nitric oxide-producing CD11b(+)Ly-6G(Gr-1)(+)CD31(ER-MP12)(+) cells in the spleen of cyclophosphamide-treated mice: implications for T-cell responses in immunosuppressed mice. Blood. 2000;95(1):212-220

89. Kumar S, Jyoti A, Keshari RS, Singh M, Barthwal MK, Dikshit M. Functional and molecular characterization of NOS isoforms in rat neutrophil precursor cells. Cytometry A. 2010;77(5):467-477.

90. Martin C, Boisson C, Haccoun M, Thomachot L, Mege JL. Patterns of cytokine evolution (tumor necrosis factor-alpha and interleukin-6) after septic shock, hemorrhagic shock, and severe trauma. Crit Care Med. 1997;25(11):1813-1819.

91. Roumen RM, et al. Cytokine patterns in patients after major vascular surgery, hemorrhagic shock, and severe blunt trauma. Relation with subsequent adult respiratory distress syndrome and multiple organ failure. Ann Surg. 1993;218(6):769-776.

92. Stone SF, Cotterell C, Isbister GK, Holdgate A, Brown SG; Emergency Department Anaphylaxis Investigators. Collaborators (14) Elevated serum cytokines during human anaphylaxis: Identification of potential mediators of acute allergic reactions. J Allergy Clin Immunol. 2009;124(4):786-92.e4.

93. Hober D, et al. Serum levels of tumor necrosis factor-alpha (TNF-alpha), interleukin-6 (IL-6), and interleukin-1 beta (IL-1 beta) in dengue-infected patients. Am J Trop Med Hyg. 1993;48(3):324-331.

94. Iyngkaran N, Yadav M, Sinniah M. Augmented inflammatory cytokines in primary dengue infection progressing to shock. Singapore Med J. 1995;36(2):218-221.

95. Kittigul L, Temprom W, Sujirarat D, Kittigul C. Determination of tumor necrosis factor-alpha levels in dengue virus infected patients by sensitive biotin-streptavidin enzyme-linked immunosorbent assay. J Virol Methods. 2000;90(1):51-57.
96. Atrasheuskaya A, Petzelbauer P, Fredeking TM, Ignatyev G. Anti-TNF antibody treatment reduces mortality in experimental dengue virus infection. FEMS Immunol Med Microbiol. 2003;35(1):33-42.

97. Bulotta S, Barsacchi R, Rotiroti D, Borgese N, Clementi E. Activation of the endothelial nitric-oxide synthase by tumor necrosis factor-alpha. A novel feedback mechanism regulating cell death. J Biol Chem. 2001;276(9):6529-6536.

98. Muhl H, Pfeilschifter J. Endothelial nitric oxide synthase: a determinant of TNFalpha production by human monocytes/macrophages. Biochem Biophys Res Commun. 2003;310(3):677-680.

99. Yoshizumi M, Perrella MA, Burnett JC Jr, Lee ME. Tumor necrosis factor downregulates an endothelial nitric oxide synthase mRNA by shortening its half-life. Circ Res. 1993;73(1):205-209.

100. Perez AB, et al. IL-10 levels in Dengue patients: some findings from the exceptional epidemiological conditions in Cuba. J Med Virol. 2004;73(2):230-234.

101. Chakravarti A, Kumaria R. Circulating levels of tumour necrosis factor-alpha and interferongamma in patients with dengue $\&$ dengue haemorrhagic fever during an outbreak. Indian J Med Res. 2006;123(1):25-30.

102. Fink J, et al. Host gene expression profiling of dengue virus infection in cell lines and patients. PLoS Negl Trop Dis. 2007;1(2):e86.

103.Ubol S, Masrinoul P, Chaijaruwanich J, Kalayanarooj S, Charoensirisuthikul T, Kasisith J. Differences in global gene expression in peripheral blood mononuclear cells indicate a significant role of the innate responses in progression of dengue fever but not dengue hemorrhagic fever.J Infect Dis. 2008;197(10):1459-1467.

104. Nguyen TH, et al. Association between sex, nutritional status, severity of dengue hemorrhagic fever, and immune status in infants with dengue hemorrhagic fever. Am J Trop Med Hyg. 2005;72(4):370-374.

105.Pang T, Cardosa MJ, Guzman MG. Of cascades and perfect storms: the immunopathogenesis of dengue haemorrhagic fever-dengue shock syndrome (DHF/DSS). Immunol Cell Biol. 2007;85(1):43-45.

106. Tessarz AS, Cerwenka A. The TREM-1/DAP12 pathway. Immunol Lett. 2008;116(2):111-116.

107. Lanier LL. Up on the tightrope: natural killer cell activation and inhibition. Nat Immunol. 2008; 9(5):495-502

108.Zompi S, et al. NKG2D triggers cytotoxicity in mouse NK cells lacking DAP12 or Syk family kinases. Nat Immunol. 2003;4(6):565-572.

109. Orr MT, et al. Ly49H signaling through DAP10 is essential for optimal natural killer cell responses to mouse cytomegalovirus infection. J Exp Med. 2009;206(4):807-817.

110.Jiang K, et al. Syk regulation of phosphoinositide 3-kinase-dependent NK cell function. J Immunol. 2002;168(7):3155-3164

111.Peng Q, Malhotra S, Torchia JA, Kerr WG, Coggeshall KM, Humphrey MB. TREM2- and DAP12dependent activation of PI3K requires DAP10 and is inhibited by SHIP1. Sci Signal. 2010;3(122):ra38.

112.Fleming I, Busse R. Molecular mechanisms involved in the regulation of the endothelial nitric oxide synthase. Am J Physiol Regul Integr Comp Physiol. 2003;284(1):R1-R12.

113. Fontana J, et al. Domain mapping studies reveal that the M domain of hsp90 serves as a molecular scaffold to regulate Akt-dependent phosphorylation of endothelial nitric oxide synthase and NO release. Circ Res. 2002;90(8):866-873.

114.Takahashi S, Mendelsohn ME. Synergistic activation of endothelial nitric-oxide synthase (eNOS) by HSP90 and Akt: calcium-independent eNOS activation involves formation of an HSP90Akt-CaM-bound eNOS complex. J Biol Chem. 2003;278(33):30821-30827.

115. Chen JX, Meyrick B. Hypoxia increases Hsp90 binding to eNOS via PI3K-Akt in porcine coronary artery endothelium. Lab Invest. 2004;84(2):182-190.

116. Xi W, Satoh H, Kase H, Suzuki K, Hattori Y. Stimulated HSP90 binding to eNOS and activation of the PI3-Akt pathway contribute to globular adiponectin-induced NO production: vasorelaxation in response to globular adiponectin. Biochem Biophys Res Commun. 2005;332(1):200-205.

117. Friedman G, Silva E, Vincent JL. Has the mortality of septic shock changed with time. Crit Care Med. 1998;26(12):2078-2086.

118. Rigau-Perez JG, Clark GG, Gubler DJ, Reiter P, Sanders EJ, Vorndam AV. Dengue and dengue haemorrhagic fever. Lancet. 1998;352(9132):971-977.

119.Cohen J, Carlet J. INTERSEPT: an international, multicenter, placebo-controlled trial of monoclonal antibody to human tumor necrosis factor-alpha in patients with sepsis. International Sepsis Trial Study Group. Crit Care Med. 1996;24(9):1431-1440.

120.Abraham E, et al. Double-blind randomised controlled trial of monoclonal antibody to human tumour necrosis factor in treatment of septic shock. NORASEPT II Study Group. Lancet. 1998;351(9107):929-933.

121. Bakker J, et al. Administration of the nitric oxide synthase inhibitor NG-methyl-L-arginine hydrochloride $(546 \mathrm{C} 88$ ) by intravenous infusion for up to 72 hours can promote the resolution of shock in patients with severe sepsis: results of a randomized, double-blind, placebo-controlled multicenter study (study no. 144-002). Crit Care Med. 2004;32(1):1-12.

122. Watson D, et al. Cardiovascular effects of the nitric oxide synthase inhibitor NG-methyl-L-arginine hydrochloride $(546 \mathrm{C} 88)$ in patients with septic shock: results of a randomized, double-blind, placebo-controlled multicenter study (study no. 144002). Crit Care Med. 2004;32(1):13-20.

123. Lopez A, et al. Multiple-center, randomized, placebocontrolled, double-blind study of the nitric oxide synthase inhibitor 546C88: effect on survival in patients with septic shock. Crit Care Med. 2004;32(1):21-30.

124.Moss ML, Sklair-Tavron L, Nudelman R. Drug insight: tumor necrosis factor-converting enzyme as a pharmaceutical target for rheumatoid arthritis. Nat Clin Pract Rheumatol. 2008;4(6):300-309.

125. Courtney KD, Corcoran RB, Engelman JA. The PI3K pathway as drug target in human cancer. J Clin Oncol. 2010;28(6):1075-1083.

126. Bakker AB, et al. DAP12-deficient mice fail to develop autoimmunity due to impaired antigen priming. Immunity. 2000;13(3):345-353.

127. Gilfillan S, Ho EL, Cella M, Yokoyama WM, Colonna M. NKG2D recruits two distinct adapters to trigger NK cell activation and costimulation. Nat Immunol. 2002;3(12):1150-1155.

128. Pasparakis M, Alexopoulou L, Episkopou V, Kollias G. Immune and inflammatory responses in TNF alpha-deficient mice: a critical requirement for TNF alpha in the formation of primary B cell follicles, follicular dendritic cell networks and germinal centers, and in the maturation of the humoral immune response. J Exp Med. 1996;184(4):1397-1411.

129.Abrams JS, Roncarolo MG, Yssel H, Andersson U, Gleich GJ, Silver JE. Strategies of anti-cytokine monoclonal antibody development: immunoassay of IL-10 and IL-5 in clinical samples. Immunol Rev. 1992; 127:5-24.

130.Tepper RI, Coffman RL, Leder P. An eosinophildependent mechanism for the antitumor effect of interleukin-4. Science. 1992;257(5069):548-551. 